\title{
Temporally Specific Roles of Ventral Tegmental Area Projections to the Nucleus Accumbens and Prefrontal Cortex in Attention and Impulse Control
}

\author{
Jacques P. Flores-Dourojeanni, ${ }^{1,2}$ Coby van Rijt, ${ }^{1}$ Marleen H. van den Munkhof, ${ }^{1}{ }^{\circ}$ Linde Boekhoudt, ${ }^{1}$ \\ Mieneke C. M. Luijendijk, ${ }^{1}{ }^{\circledR}$ Louk J. M. J. Vanderschuren, ${ }^{2 *}$ and ${ }^{\circledR}$ Roger A. H. Adan ${ }^{1,3 *}$ \\ ${ }^{1}$ Brain Center Rudolf Magnus, Department of Translational Neuroscience, University Medical Center Utrecht, Utrecht 3508 GA, The Netherlands, \\ ${ }^{2}$ Department of Population Health Sciences, Animals in Science and Society, Faculty of Veterinary Medicine, Utrecht University, Utrecht 3584 CM, \\ The Netherlands, and ${ }^{3}$ Institute of Neuroscience and Physiology, The Sahlgrenska Academy at the University of Gothenburg, Gothenburg SE405 30 , \\ Sweden
}

Deficits in impulse control and attention are prominent in the symptomatology of mental disorders such as attention deficit hyperactivity disorder (ADHD), substance addiction, schizophrenia, and bipolar disorder, yet the underlying mechanisms are incompletely understood. Frontostriatal structures, such as the nucleus accumbens (NAcb), the medial prefrontal cortex (mPFC), and their dopaminergic innervation from the ventral tegmental area (VTA) have been implicated in impulse control and attention. What remains unclear is how the temporal pattern of activity of these VTA projections contributes to these processes. Here, we optogenetically stimulated VTA dopamine (DA) cells, as well as VTA projections to the NAcb core (NAcbC), NAcb shell (NAcbS), and the mPFC in male rats performing the 5-choice serial reaction time task (5-CSRTT). Our data show that stimulation of VTA DA neurons, and VTA projections to the NAcbC and the mPFC immediately before presentation of the stimulus cue, impaired attention but spared impulse control. Importantly, in addition to reducing attention, activation of VTA-NAcbS also increased impulsivity when tested under a longer intertrial interval (ITI), to provoke impulsive behavior. Optogenetic stimulation at the beginning of the ITI only partially replicated these effects. In sum, our data show how attention and impulsivity are modulated by neuronal activity in distinct ascending output pathways from the VTA in a temporally specific manner. These findings increase our understanding of the intricate mechanisms by which mesocorticolimbic circuits contribute to cognition.

Key words: 5-CSRTT; accumbens; attention; dopamine; impulsivity; VTA

Significance Statement

Deficits in impulse control and attention are prominent in the symptomatology of several mental disorders, yet the brain mechanisms involved are incompletely understood. Since frontostriatal circuits have been implicated in impulse control and attention, we here examined the role of ascending projections from the midbrain ventral tegmental area (VTA) to the nucleus accumbens (NAcb) and prefrontal cortex (PFC). Using optogenetics to individually stimulate these projections with timelocked precision, we distinguished the role that each of these projections plays, in both impulse control and attention. As such, our study enhances our understanding of the neuronal circuitry that drives impulsive and attentive behavior.

Received Feb. 20, 2020; revised Nov. 30, 2020; accepted Dec. 11, 2020.

Author contributions: J.P.F.-D., C.v.R., M.H.v.d.M., L.J.M.J.V., and R.A.H.A. designed research; J.P.F.-D., C.v.R., M.H.v.d.M., L.B., M.C.M.L., L.J.M.J.V., and R.A.H.A. performed research; J.P.F.-D., C.v.R., M.H.v.d.M., L.J.M.J.V., and R.A.H.A. analyzed data; J.P.F.-D., M.H.v.d.M., and R.A.A. wrote the paper.

This work was supported by the Netherlands Organization for Scientific Research (NWO) Graduate Program Fellowship (J.P.F.-D.). R.A.H.A. and L.J.M.J.V. were supported by the European Union Seventh Framework Program Grant 607310 (Nudge-It) and the Netherlands Organization for Health Research and Development (ZonMw) Grant 91214093 (Shining light on loss of control).

*L.J.M.J.V. and R.A.H.A. contributed equally to this work.

The authors declare no competing financial interests.

Correspondence should be addressed to Roger A. H. Adan at r.a.h.adan@umcutrecht.nl.

https://doi.org/10.1523/JNEUROSCI.0477-20.2020

Copyright $\odot 2021$ the authors

\section{Introduction}

Attention and impulse control are cognitive processes which are essential for adaptive behavior. Deficits in these processes contribute to the symptomatology of mental disorders such as schizophrenia, bipolar disorder, substance addiction and attention deficit hyperactivity disorder (ADHD; Moeller et al., 2001; de Wit, 2009; Fineberg et al., 2014; Dalley and Robbins, 2017). A better understanding of the precise neural underpinnings of attention and impulse control would therefore open new avenues to treat these disorders.

The 5-choice serial reaction time task (5-CSRTT) is a translational task of cognition, widely used to study the neural circuitry 
of impulse control and attention (Rosvold et al., 1956; Robbins, 2002; Bari et al., 2008; Voon et al., 2014). In this task, attention is assessed by measuring how often and accurately an animal responds to an instruction cue, whereas impulsive action is evaluated by testing how well an animal can withhold from responding until the cue is presented. Impulse control and attention in the 5-CSRTT are modulated by frontostriatal circuits and their monoaminergic innervation, of which dopamine (DA) has been most widely investigated (Pattij and Vanderschuren, 2008; Eagle and Baunez, 2010; Baarendse and Vanderschuren, 2012; Dalley and Robbins, 2017). We recently found that chemogenetically facilitating the activity of DA neurons in the ventral tegmental area (VTA), the main DAergic input to the nucleus accumbens (NAcb) and the medial prefrontal cortex (mPFC), increased the number of omitted responses, without altering impulsive behavior (Boekhoudt et al., 2017). This latter finding is inconsistent with previous work implicating NAcb DA in impulsive behavior in the 5-CSRTT (Cole and Robbins, 1987, 1989; Pattij et al., 2007; Pezze et al., 2007; Besson et al., 2010; Economidou et al., 2012). Importantly, within the $\mathrm{NAcb}$, its core and shell sub-regions have been proposed to have distinct roles in modulating impulsive behavior (Dalley et al., 2007; Pattij et al., 2007; Sesia et al., 2008; Besson et al., 2010; Economidou et al., 2012), so that simultaneous chemogenetic stimulation of core and shell DA neurotransmission may induce effects on impulsivity that cancel out each other. Regarding attention, infusion of DA receptor antagonists into the $\mathrm{NAcb}$ has been found to increase the number of omissions (Pattij et al., 2007; Pezze et al., 2007). However, infusions of DA agonists yielded mixed effects (Cole and Robbins, 1987; Pezze et al., 2007; Besson et al., 2010; Economidou et al., 2012). In other work, lesions of the mPFC increased premature responses and omissions (Chudasama et al., 2003) and decreased response accuracy (Passetti et al., 2002) whereas intra-mPFC infusion of methylphenidate only marginally affected omissions (Economidou et al., 2012). These distinctions highlight the need to further assess the role of forebrain DA innervation in attention and impulse control.

In the present study, we exploited the temporal precision of optogenetic methods to assess how ascending VTA projections contribute to attention and impulse control in the 5-CSRTT. We separately stimulated VTA DA neurons as well as the VTA projections toward the mPFC, NAcb core (NAcbC), and NAcb shell (NAcbS), during baseline conditions, as well as during sessions with an elongated intertrial interval (ITI), resulting in increased impulsivity (Dalley et al., 2007; Baarendse and Vanderschuren, 2012; Boekhoudt et al., 2017). We expected that optogenetic stimulation of specific populations of VTA neurons within particular time-windows in the 5-CSRTT would reveal effects that may have been obscured after pharmacological or chemogenetic manipulations. Specifically, we predicted that VTA DA neuron activation alters attentive but not impulsive behavior, consistent with our previous chemogenetic study (Boekhoudt et al., 2017). Moreover, on the basis of previous pharmacological studies, we expected that activation of VTA-NAcbS, VTA-NAcbC and VTA-mPFC projections would decrease attention (Cole and Robbins, 1987; Pezze et al., 2007; Besson et al., 2010; Economidou et al., 2012). We also predicted changes in premature responses when activating VTA-NAcbC or VTA-NAcbS projections, resonating with the mixed findings in the literature (Murphy et al., 2000; Pezze et al., 2007; Besson et al., 2010; Economidou et al., 2012).

\section{Materials and Methods}

\section{Animals}

All animals were bred in-house by crossing heterozygote male rats expressing the Cre enzyme in tyrosine hydroxylase (TH)-expressing neurons (TH::Cre+/-; 3.1 line; Witten et al., 2011) with wild-type female Long-Evans rats (Charles River). Twenty-two TH::Cre+/males and 40 male wild-type (TH::Cre-/-) littermates were used in this study. The animals were socially housed in Type III Macrolon cages until surgery, after which they were individually housed to prevent damage to the chronic fibers. They were housed under a 12/ $12 \mathrm{~h}$ reverse day/night cycle (lights on at 7 P.M.) in a temperaturecontrolled $\left(20-22^{\circ} \mathrm{C}\right)$ and humidity-controlled $(60-70 \%)$ room. All animals were approximately three months old and weighed 250-300 $g$ when 5-CSRTT training commenced. They were food restricted to $90 \%$ of the free feeding weight throughout the experiment. All experiments were approved by the Animal Ethics committee of Utrecht University and were conducted in accordance with Dutch Laws (Wet op de Dierproeven, 1996) and European guidelines (86/ 609/EEC).

\section{Surgery}

Animals were anesthetised by intramuscular injection of Hypnorm $(0.315 \mathrm{mg} / \mathrm{kg}$ fentanyl, $10 \mathrm{mg} / \mathrm{kg}$ fluanisone; Janssen Pharmaceutica) and placed in a stereotaxic frame (Kopf Instruments). Xylocaine (lidocaine $100 \mathrm{mg} / \mathrm{ml}$, AstraZeneca) was applied to the skull as a local analgesic. All animals (except for the control group, see below) received a 1ul bilateral injection of AAV5-Ef1a-DIO-hChR2-(H134R)-EYFP (7.4 × 1012 molecules/ml; UNC Vector Core) into the VTA $(-5.80 \mathrm{AP},+1.60 \mathrm{ML}$, $-8.40 \mathrm{DV} ; 5^{\circ}$ angle) along with a chronic optic fiber $(210-240 \mu \mathrm{m}$, 0.22 NA; Precision Fiber Products) inserted $0.5 \mathrm{~mm}$ above the injection site $(-7.90 \mathrm{DV})$. TH::Cre- $/$ - animals also received $0.5-\mu$ l bilateral injections of Cav2-Cre $(1.0 \times 1012$ molecules $/ \mathrm{ml})$ into either the NAcbC $\left(+1.20 \mathrm{AP},+1.60 \mathrm{ML},-6.80 \mathrm{DV} ; 0^{\circ}\right.$ angle), the NAcbS (+1.20 AP, $+2.70 \mathrm{ML},-7.50 \mathrm{DV} ; 10^{\circ}$ angle), or the $\mathrm{mPFC}(+2.70 \mathrm{AP},+1.20 \mathrm{ML}$, $-5.70 \mathrm{DV} ; 10^{\circ}$ angle). The control group consisted of $\mathrm{TH}:: \mathrm{Cre}+/-$ rats that received infusion of an inactive virus (AAV5-Ef1a-DIO-EYFP, 3 $\times 1012$ molecules/ml; UNC Vector Core) into the VTA. Animals were given Carprofen $(5.0 \mathrm{mg} / \mathrm{kg}$ Carporal, AST Farma) for pain relief, immediately after surgery and for two consecutive days thereafter.

\section{Behavioral set-up}

5-CSRTT training and testing was conducted as previously described (Baarendse and Vanderschuren, 2012; Boekhoudt et al., 2017). In brief, the rats were trained to respond into one of five nose-poke holes, that pseudo-randomly illuminated for $1 \mathrm{~s}$ (5-s limited hold), to earn sucrose pellets. Once all animals performed at criterion (i.e., $>70 \%$ correct responses) they underwent surgery. After surgery, all animals were retrained and habituated to being attached to optic fibers, and to the laser light, until performance levels returned to presurgery levels, which took approximately two to three weeks.

A nose-poke into the illuminated hole within the limited hold period was counted as a correct response, rewarded by delivery of a sucrose pellet. After a correct response, the next trial was initiated when the animal retrieved the sucrose pellet, as detected by an entry into the food-port. A response in one of the non-illuminated holes was recorded as an incorrect response, a failure to respond within the limited hold period as an omission, and a nose-poke during the ITI as a premature response. Incorrect responses, omissions, and premature responses were punished with a 5-s timeout, during which stimulus lights were switched off and the house light was switched on; the next trial commenced after the timeout. Repeated responses in one of the nose-poke holes were recorded as perseverative responses but had no programmed consequences. Accuracy was defined as percentage of correct responses relative to total responses [correct/(correct + incorrect) $\times 100 \%]$. Latencies to respond (premature, correct, incorrect, and food magazine entry) were recorded as well. Sessions lasted for 100 trials or $30 \mathrm{~min}$, whichever occurred first. During the 7-s ITI challenge, the number of trials was increased to 200 and the duration to $1 \mathrm{~h}$ to incorporate within session. 


\section{Experiments}

Five groups of rats were tested. The first group consisted of TH::Cre $+/-$ animals $(n=16)$, used to target DAergic neurons in the VTA. Wild-type $\mathrm{TH}:: \mathrm{Cre}-/$ - littermates were subdivided further into three groups, to target projections from the VTA to the NAcbC $(n=11)$; projections from the VTA to the NAcbS $(n=9)$; to target projections from the VTA to the mPFC $(n=13)$. The fifth group $(n=5)$ consisted of TH::CRE+/- rats that received infusion of a control virus (AAV5-Efla-DIO-EYFP) virus into the VTA. The effects of optogenetic stimulation were tested under three conditions: (1) baseline 5-s ITI conditions with stimulation at the end of the ITI; (2) under a longer ITI condition (i.e., $7 \mathrm{~s}$ instead of $5 \mathrm{~s}$ ), to provoke premature responding (Dalley et al., 2007; Baarendse and Vanderschuren, 2012; Boekhoudt et al., 2017); (3) under 5-s ITI conditions with a stimulation time point starting at the onset of the ITI, instead of before presentation of the stimulus cue. All groups progressed through the three conditions in the order presented except for the VTA DA group which began with the ITI onset stimulation, then was tested under the 5-s ITI baseline (end of ITI stimulation) and ended with the 7-s ITI condition.

\section{Optogenetics}

Lasers (Changchun New Industries Optoelectronics) were attached to rotary joints (DORIC) via a mono fiber-optic patch cord (NA 0.22, 200$\mu \mathrm{m}$ core diameter, DORIC). The rotary joint was connected to chronic fibers implanted into the animal's brain via two patch cords (NA 0.22 , $127-130 \mu \mathrm{m}$, THORLABS). During testing and training, a small piece of black tape was wrapped around the chronic optic fibers to prevent light leakage from the laser. During "mock" stimulations, a small piece of gray foam was inserted inside the sleeve connecting the patch cords to the chronic optic fibers to prevent light from entering the brain but allowing the laser to minimally shine on the head mount.

All stimulations were done for $3 \mathrm{~s}$ at a frequency of $20 \mathrm{~Hz}$ with $5-\mathrm{ms}$ pulse width to maximize DA release (Adamantidis et al., 2011). During baseline sessions, the laser would turn on at $1.5 \mathrm{~s}$ into the ITI and turn off $3 \mathrm{~s}$ later, $0.5 \mathrm{~s}$ before the onset of the stimulus cue. During the 7-s ITI challenge sessions, the laser would turn on $3.5 \mathrm{~s}$ into the ITI and turn off $3 \mathrm{~s}$ later, again $0.5 \mathrm{~s}$ before stimulus cue onset. During the ITI onset sessions, the laser would turn on immediately at the onset of the ITI and turn off $3 \mathrm{~s}$ later, i.e., $2 \mathrm{~s}$ before stimulus cue onset. The laser was turned off before cue onset to avoid laser light overflow from interfering with the stimulus cue. Moreover, stimulating VTA projections during or after cue presentation may have interfered with reward prediction error processes (Schultz et al., 1997), hence stimulation was kept within the ITI timeframe. Mock stimulations were always done the day before stimulation. Laser intensity was maintained at approximately $10 \mathrm{~mW}$, which was measured before and after stimulation. If a session showed a substantial decrease in laser intensity (more than $2 \mathrm{~mW}$ ), that session would be discarded and repeated the next week. In total each animal received three laser stimulation sessions (5-s ITI, 7-s ITI, and onset 5-s ITI), excluding any sessions that had to be repeated because of laser intensity issues. Animals only underwent optogenetic stimulation if they had shown stable performance ( $<10 \%$ variation in accuracy and omissions) over the previous $2 \mathrm{~d}$. Animals were removed from the experiment if they lost their chronic fiber headcaps.

\section{Immunohistochemistry}

Immunohistochemistry was performed as previously described (Boekhoudt et al., 2017). Briefly, animals were anaesthetized using a lethal dose of pentobarbital $(0.1 \mathrm{ml} / 100 \mathrm{~g}$; Euthanimal, Alfasan BV) and transcardially perfused with $0.9 \%$ saline followed by $4 \%$ paraformaldehyde (PFA) in PBS. Brain slices $(40 \mu \mathrm{m})$ were made using a Leica cryostat and subsequently stained for $\mathrm{TH}$ and enhanced yellow fluorescent protein (EYFP) using mouse anti-TH (EMD Millipore, 1:500) and chicken anti-EYFP (Sigma-Aldrich, 1:500). Animals that showed no ChR2 expression in the VTA were removed from the analysis (13 animals in total across all groups).

\section{Data analysis}

All statistical analyses were performed using GraphPad Prism (GraphPad Software). For tests under baseline conditions, mock and stimulation sessions were compared. For the long ITI session, we compared laser and no laser trials within a session. Comparisons between sessions or trials were done using a paired Student's $t$ test. When data were not normally distributed (as checked using a Shapiro-Wilk test), a Wilcoxon matched-pairs signed rank test was performed instead. When calculating differences between latencies, some animals failed to make premature or incorrect responses thereby reducing the number of paired comparisons for that particular parameter. In view of the large number of $t$ tests performed in this study, rather than correcting for multiple testing, we chose a low $\alpha$ significance level of 0.025 to reduce the chance of Type I errors. As the parameters were not independent, correcting for all comparisons would be too stringent.

One animal from the TH::Cre $+/-$ control group, three animals from the TH::Cre-/- NAcbC group, one animal from the TH::Cre-/NAcbS and one animal from the mPFC group were removed because of optic fiber loss or lack of ChR-2 expression. Additionally, one animal from the TH::Cre-/ - NAcbC group died during surgery and another animal from the TH::Cre- $/-$ mPFC group was removed because of incorrect optic fiber placement (wrong angle). Furthermore, before the 7-s ITI stimulation session, 6 animals from the VTA DA group, three animals from the NAcbC group, and four animals from the mPFC group were removed from the study as a result of losing one or more of their optic fibers. For the ITI onset stimulation, one animal was removed from the NAcbC group and 2 animals were removed from the PFC group. Within the VTA DA group, one animal was removed from the study before 5-s ITI baseline stimulation because of fiber optic loss.

\section{Results}

Activating VTA dopaminergic neurons decreases attention We stimulated VTA DA neurons in TH::Cre+/- rats in vivo to determine how time-locked increments in DA neurotransmission before stimulus cue presentation affect 5-CSRTT performance (Fig. $1 A-G$ ). Stimulation of VTA DA neurons reduced the number of correct responses $\left(t_{(14)}=5.4, p=0.0001\right.$; Fig. $\left.1 B\right)$ and increased errors of omission $\left(t_{(14)}=5.11, p=0.0002\right.$; Fig. $\left.1 E\right)$. Incorrect responses, accuracy and premature responses were not affected $\left[t_{(14)}=0.23, p=0.81\right.$ (Fig. $1 C$ ); $t_{(14)}=1.47, p=0.16$ (Fig. $1 D) ; t_{(14)}=0.33, p=0.75$, respectively $($ Fig. $1 F)$ ]. In addition, latency to correct responses $\left(t_{(14)}=4.05, p=0.0012\right.$; Table 1$)$ were increased. The latency to retrieve the reward $\left(t_{(14)}=0.06\right.$, $p=0.95$; Fig. $1 G)$, latency to premature responses $\left(t_{(14)}=0.05\right.$, $p=0.95$; Table 1$)$ and perseverative responses $(W=-40, p=$ 0.12 ; Table 1) remained unaffected, whereas there was a trend toward an increased latency to incorrect responses $\left(t_{(14)}=2.35\right.$, $p=0.03$; Table 1). Optogenetic stimulation in control animals did not alter any of the parameters in the 5-CSRTT $\left[t_{(4)}=0.63\right.$, $p=0.56$ (Fig. $2 A$ ); $t_{(4)}=1.18, p=0.3$ (Fig. $\left.2 B\right) ; t_{(4)}=0.94, p=0.40$ (Fig. $2 C$ ); $t_{(4)}=1.81, p=0.14$ (Fig. $2 D$ ); $t_{(4)}=1.39, p=0.23$ (Fig. $2 E) ; t_{(4)}=0.76, p=0.49$ (Fig. $\left.2 F\right)$.

\section{Stimulating VTA-NAcbS projections reduces attention}

Stimulation of VTA projections to the NAcbS (Fig. 3A-G) significantly reduced the number of correct responses, and increased omissions $\left[t_{(8)}=3.86, p=0.005\right.$ (Fig. $3 B$ ) and $t_{(8)}=3.26, p=0.01$ (Fig. $3 E$ ), respectively]. Stimulation of this pathway tended to increase the number of premature responses $\left(t_{(8)}=2.49\right.$, $p=0.037$; Fig. $3 F$ ); this trend was driven by five out of nine animals. Stimulation had no effect on incorrect responses, accuracy, or the latency to retrieve the reward $\left[t_{(8)}=1.31, p=0.29\right.$ (Fig. $3 C$ ); $t_{(8)}=1.44, p=0.19$ (Fig. $3 D$ ); $t_{(8)}=1.42, p=0.19$ (Fig. $3 G$ ), respectively]. Incorrect responses were made significantly sooner during stimulation $\left(t_{(8)}=3.97, p=0.004\right.$; Table 1$)$, but the latency to correct responses $\left(t_{(8)}=0.4, p=0.70\right.$; Table 1$)$, premature responses $\left(t_{(8)}=1.57, p=0.16\right.$; Table 1$)$ and the number of 
A
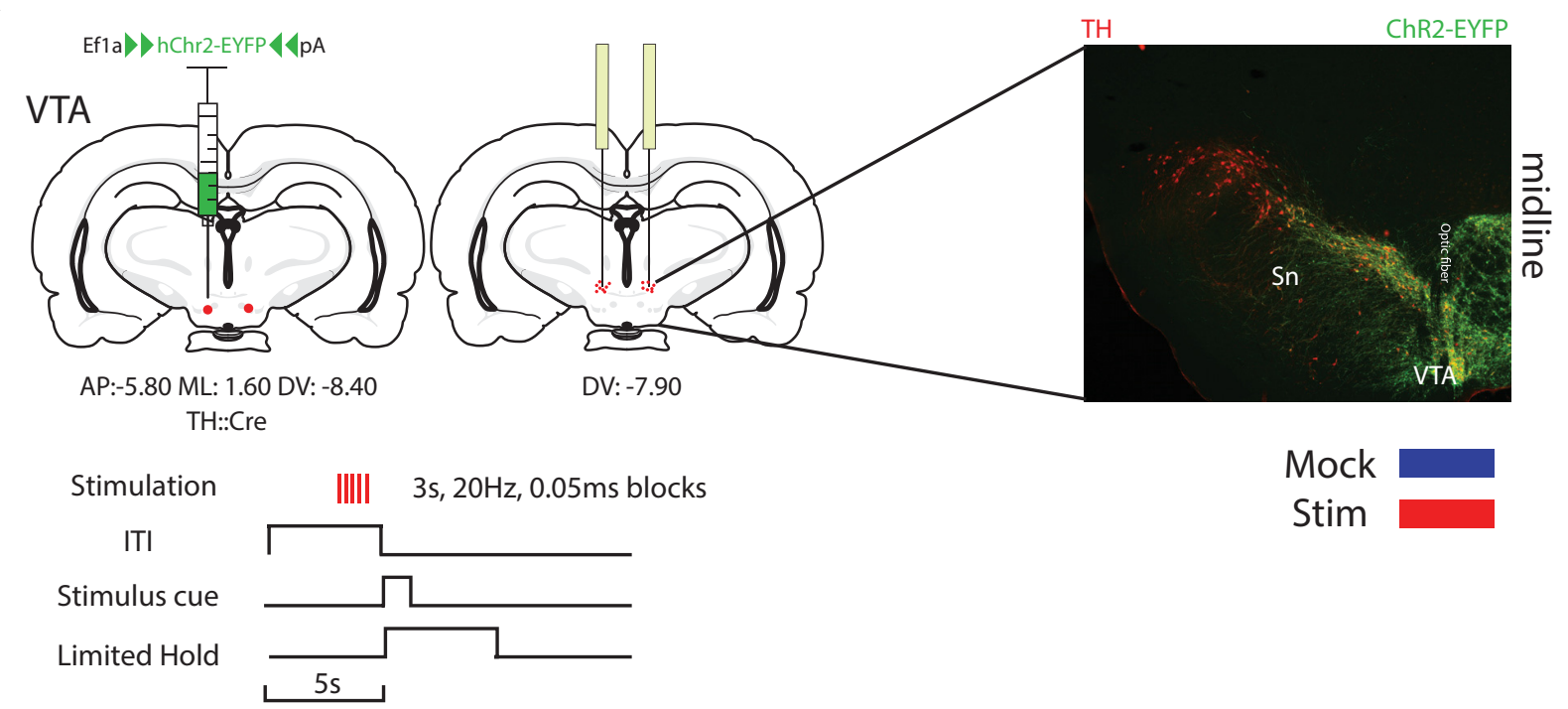

B

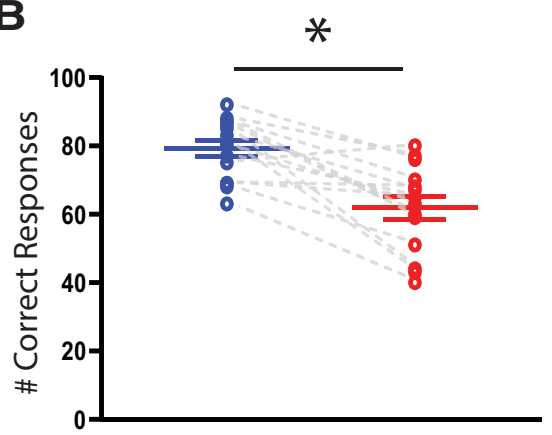

E

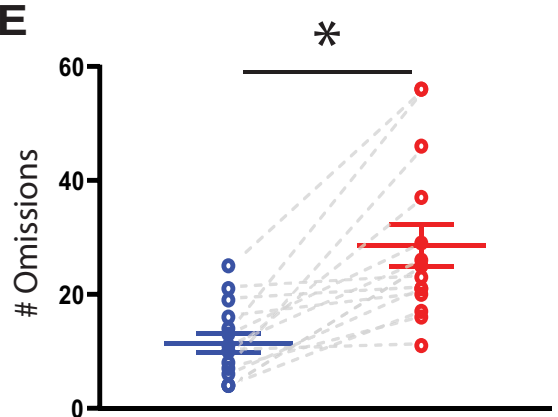

C

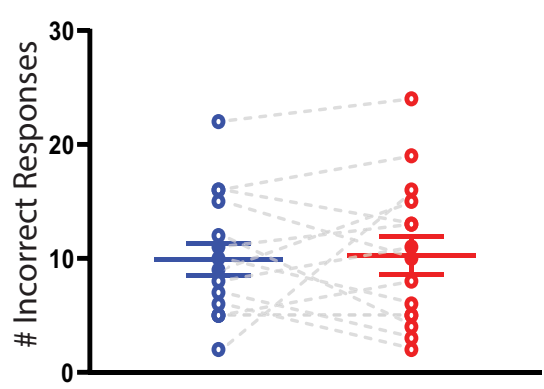

$\mathbf{F}$

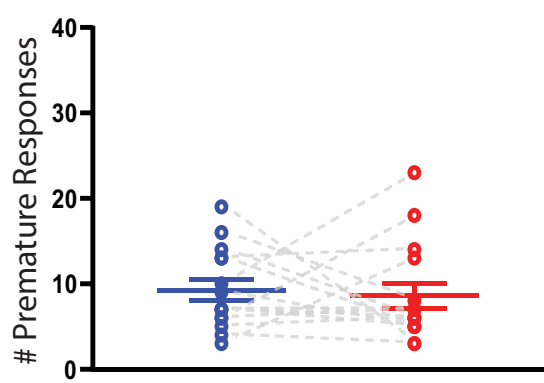

D

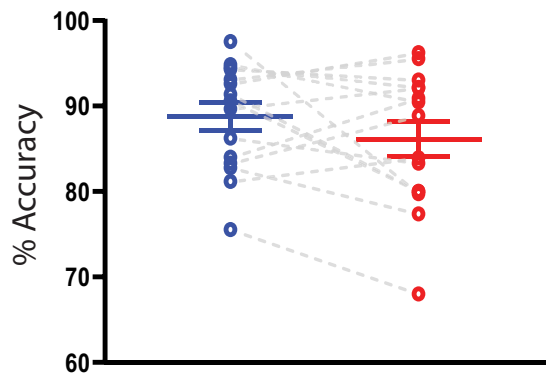

G

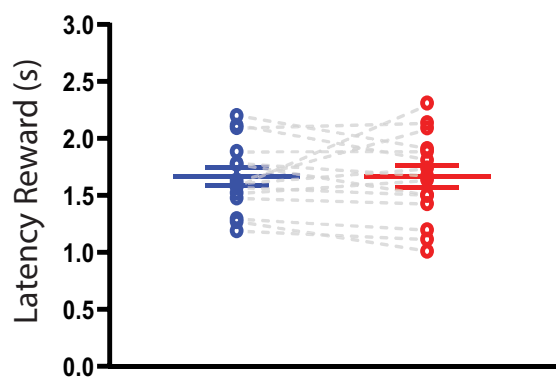

Figure 1. Stimulation of VTA DA neurons during the 5-CSRTT in TH::Cre+/- rats. $A$, Infusion of the Cre-dependent AAV5-Ef1a-DI0-hChR2-(H134R)-EYFP viral vector into the VTA of TH:: Cre + I- rats (left). Immunofluorescence of TH (red) and ChR2-EYFP (green) in the VTA (right). Diagram depicting the 5-CSRTT with an ITI of $5 \mathrm{~s}$ and a stimulus cue light of $1 \mathrm{~s}$ (bottom). $\boldsymbol{B}-\mathbf{G}$, Correct responses, incorrect responses, accuracy, omissions, premature responses, and latency to retrieve the reward during mock and stimulation sessions, respectively $(n=15)$. Stimulation took place in the last $3 \mathrm{~s}$ of the ITI at $20 \mathrm{~Hz}$. Data are presented as mean $\pm \mathrm{SEM} ; * p<0.025$ when compared with mock stimulation (paired sample Student's $t$ test); \# indicates a trend $0.025<p<0.05$.

perseverative responses $(W=-18, p=0.30$; Table 1$)$ remained unaltered.

\section{Stimulating VTA-NAcbC projections impairs attention}

Stimulation of VTA projections to the NAcbC (Fig. $4 A-G$ ) decreased the number of correct responses $\left(t_{(10)}=3.56\right.$, $p=0.005$; Fig. $4 B)$ and increased errors of omission $\left(t_{(10)}=3.81\right.$, $p=0.003$; Fig. $4 E$ ). Incorrect responses, accuracy and premature responses remained unchanged $\left[t_{(10)}=1.01, p=0.3\right.$ (Fig. $4 C$ ); $t_{(10)}=1.28, p=0.2$ (Fig. $\left.4 D\right) ; t_{(10)}=0.73, p=0.5$ (Fig. $4 F$ ), respectively]. The number of perseverative responses $\left(t_{(10)}=1.15\right.$, $p=0.28$; Table 1$)$ and the latency to retrieve the reward $\left(t_{(10)}=\right.$ $2.25, p=0.05$; Fig. $4 G)$ latency to correct $\left(t_{(10)}=0.63, p=0.54\right.$; Table 1$)$, latency to premature $\left(t_{(10)}=0.96, p=0.36\right.$; Table 1$)$ and latency to incorrect responses $\left(t_{(9)}=0.81, p=0.43\right.$; Table 1$)$ were not affected by stimulation of the VTA-NAcbC pathway.

\section{Stimulating VTA-mPFC projections decreases attention}

Stimulating the VTA projection to the MPFC (Fig. $5 A$ ) evoked a decrease in accuracy $\left(t_{(12)}=4.6, p=0.0005\right.$; Fig. $\left.5 D\right)$ and increased the number of incorrect responses $\left(t_{(12)}=4.85\right.$, $p=0.0004$; Fig. $5 C)$. Errors of omission $\left(t_{(12)}=0.23, p=0.82\right.$; Fig. 
Table 1. Summary of perseverative responses and latency results in the 5-CSRTT

\begin{tabular}{|c|c|c|c|c|c|c|c|c|c|c|c|}
\hline & & \multirow{2}{*}{\multicolumn{2}{|c|}{ Perseverative responses }} & \multicolumn{8}{|l|}{ Latencies } \\
\hline & & & & \multicolumn{2}{|l|}{ Correct } & \multicolumn{2}{|l|}{ Reward } & \multicolumn{2}{|l|}{ Premature } & \multicolumn{2}{|l|}{ Incorrect } \\
\hline & & Mock & Stim & Mock & Stim & Mock & Stim & Mock & Stim & Mock & Stim \\
\hline & $7-\mathrm{s} \mid \mathrm{TI}$ & $3.8 \pm 1.7$ & $1.8 \pm 0.1$ & $0.6 \pm 0.03$ & $0.7 \pm 0.04$ & $1.6 \pm 0.2$ & $1.6 \pm 0.2$ & $3.9 \pm 0.3$ & $3.7 \pm 0.6$ & $0.8 \pm 0.2$ & $1.1 \pm 0.2$ \\
\hline & onset & $11.8 \pm 6.4$ & $5.6 \pm 2.6$ & $0.7 \pm 0.04$ & $0.7 \pm 0.03$ & $1.6 \pm 0.07$ & $1.5 \pm 0.06$ & $4.0 \pm 0.1$ & $3.9 \pm 0.1$ & $1.5 \pm 0.1$ & $1.9 \pm 0.1$ \\
\hline NAcbS & $5-\mathrm{s} \mid \mathrm{TI}$ & $4.7 \pm 1.7$ & $3.3 \pm 0.1$ & $0.6 \pm 0.02$ & $0.6 \pm 0.03$ & $1.7 \pm 0.07$ & $1.6 \pm 0.06$ & $4.1 \pm 0.1$ & $3.9 \pm 0.2$ & $2.2 \pm 0.2$ & $1.4 \pm 0.1$ \\
\hline \multirow[t]{3}{*}{$\mathrm{NAcbC}$} & $5-\mathrm{s} \mid \mathrm{TI}$ & $2.5 \pm 0.6$ & $1.9 \pm 0.5$ & $0.6 \pm 0.04$ & $0.6 \pm 0.03$ & $1.5 \pm 0.1$ & $1.4 \pm 0.1$ & $3.6 \pm 0.2$ & $3.3 \pm 0.2$ & $2.1 \pm 0.3$ & $1.9 \pm 0.2$ \\
\hline & 7-s ITI & $1.1 \pm 0.5$ & $1.4 \pm 0.5$ & $0.6 \pm 0.04$ & $0.6 \pm 0.06$ & $1.5 \pm 0.1$ & $1.5 \pm 0.1$ & $3.7 \pm 0.5$ & $3.4 \pm 0.5$ & $1.3 \pm 0.1$ & $1.2 \pm 0.1$ \\
\hline & onset & $2.1 \pm 0.6$ & $2.4 \pm 0.9$ & $0.7 \pm 0.04$ & $0.8 \pm 0.06$ & $1.5 \pm 0.2$ & $1.5 \pm 0.2$ & $3.8 \pm 0.3$ & $4.1 \pm 0.2$ & $2.0 \pm 0.3$ & $2.1 \pm 0.2$ \\
\hline \multirow[t]{3}{*}{$\mathrm{mPFC}$} & $5-s|T|$ & $4.2 \pm 0.9$ & $2.7 \pm 0.9$ & $0.7 \pm 0.05$ & $0.7 \pm 0.04$ & $1.5 \pm 0.07$ & $1.5 \pm 0.06$ & $3.7 \pm 0.2$ & $3.3 \pm 0.4$ & $2.0 \pm 0.3$ & $1.8 \pm 0.2$ \\
\hline & 7-s ITI & $1.7 \pm 1.2$ & $1.2 \pm 1.4$ & $0.5 \pm 0.07$ & $0.6 \pm 0.08$ & $1.5 \pm 0.2$ & $1.5 \pm 0.2$ & $4.4 \pm 0.4$ & $4.0 \pm 0.4$ & $1.0 \pm 0.2$ & $1.5 \pm 0.5$ \\
\hline & onset & $3.0 \pm 0.9$ & $2.0 \pm 1.0$ & $0.6 \pm 0.02$ & $0.6 \pm 0.04$ & $1.6 \pm 0.08$ & $1.7 \pm 0.08$ & $3.8 \pm 0.1$ & $3.8 \pm 0.2$ & $1.7 \pm 0.4$ & $1.7 \pm 0.3$ \\
\hline
\end{tabular}

This table presents the mean number of perseverative responses, the latency to make a correct response, the latency to collect the reward, the latency to make a premature response, and the latency to make an incorrect response for mock and laser stimulation sessions. The values are presented for the stimulation of the following: VTA DA neurons, VTA projections to the NAcbS, VTA projections to the NAcbC, and VTA projections to the mPFC. The three task parameters shown here are baseline sessions 5-s ITI sessions where stimulation took place at the end of the ITI (before cue), challenge sessions where the ITI was increased to $7 \mathrm{~s}$ and stimulation took place at the end of the ITI and 5-s ITI session where stimulation took place at beginning of the ITI (ITI onset). Bold italics represents $p<0.025$ when compared with mock stimulation trials (paired samples Student's $t$ test or Wilcoxon's signed-ranked test when not normally distributed).

\section{YFP controls}

\section{A}
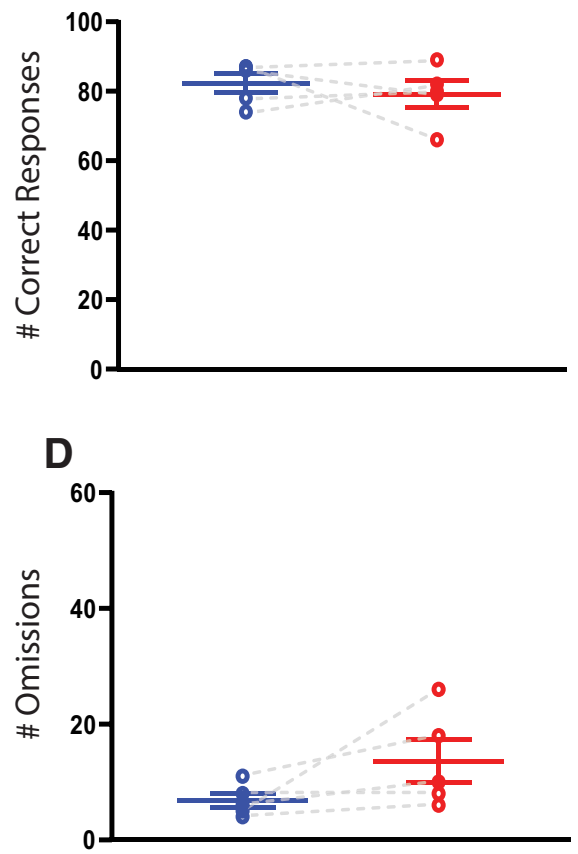

B

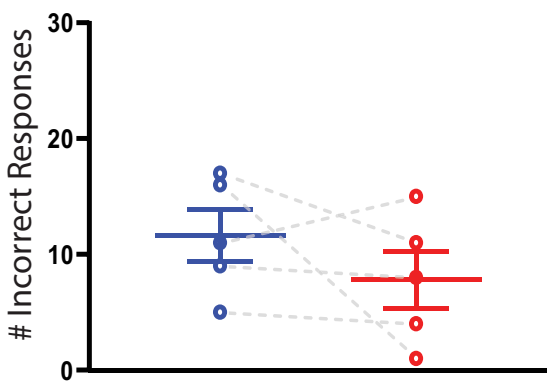

$E$

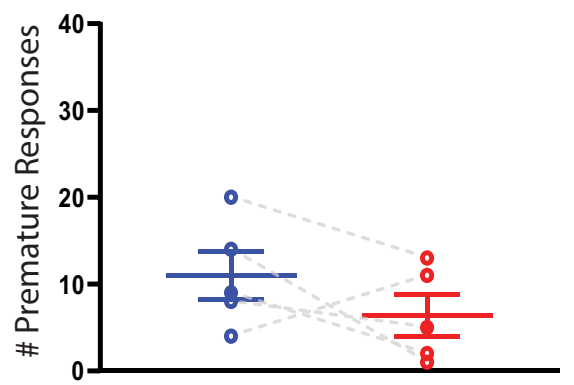

Mock

Stim
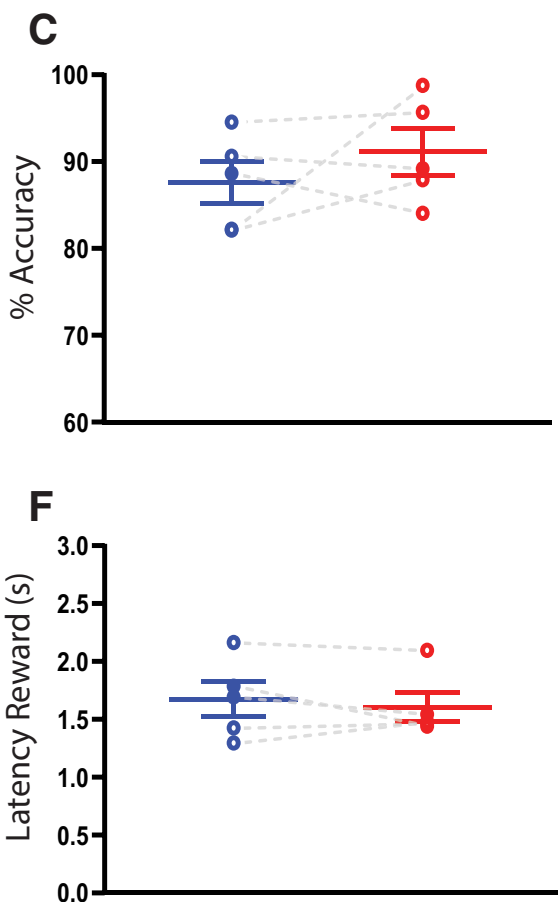

Figure 2. Stimulation of VTA DA neurons in YFP control TH::Cre+/- animals during the 5-CSRTT. A-F, Correct responses, incorrect responses, accuracy, omissions, premature responses, and latency to reward during mock and laser sessions, respectively $(n=5)$. Data are presented as mean $\pm \mathrm{SEM} * p<0.025$ when compared with mock stimulation session (paired samples Student's $t$ test); \# indicates a trend $0.025<p<0.05$.

$5 E)$, and premature responses $\left(t_{(12)}=0.4, p=0.7\right.$; Fig. $\left.5 F\right)$, were not affected by stimulation, but there was a trend toward a decrease in the number of correct responses $t_{(12)}=$ $2.2, p=0.046$; Fig. $5 B)$. Additionally, latency to reward $\left(t_{(12)}=0.04, p=0.9719\right.$; Fig. $\left.5 G\right)$ as well as perseverative responses, and correct, premature, and incorrect latencies were not affected by stimulation $(W=-27, p=0.17 ; W=$ $20, p=0.46 ; W=-31, p=0.97 ; t_{(11)}=1.3, p=0.23$, respectively; Table 1).
Effect of VTA DA, VTA-NAcbS, VTA-NAcbC, and VTAmPFC stimulation during a long ITI challenge

The 7-s ITI challenges were conducted within-session as shown in Figure $7 A$. Stimulation of VTA DA neurons during a 7-s ITI (Fig. $6 B-F)$ reduced the number of correct responses $\left(t_{(8)}=3.4\right.$, $p=0.01$; Fig. $6 B)$, increased the number of omissions $\left(t_{(8)}=3.2\right.$, $p=0.012$; Fig. $6 E$ ) but did not alter premature responses $\left(t_{(8)}=\right.$ $0.32, p=0.75$; Fig. $6 F)$, incorrect responses $\left(t_{(8)}=1.31, p=0.23\right.$; Fig. $6 C)$ or accuracy $\left(t_{(8)}=1.7, p=0.13\right.$; Fig. $\left.6 D\right)$. Perseverative 
A

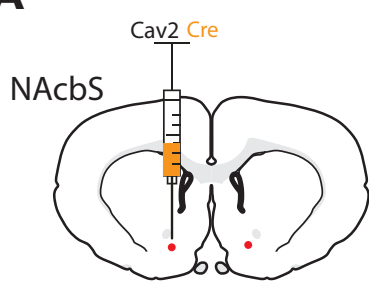

AP: $1.20 \mathrm{ML}: 2.70 \mathrm{DV}:-7.50$

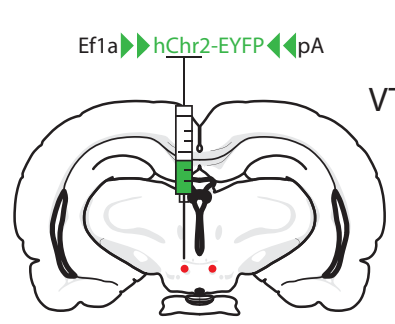

AP:-5.80 ML: 1.60 DV: -8.40

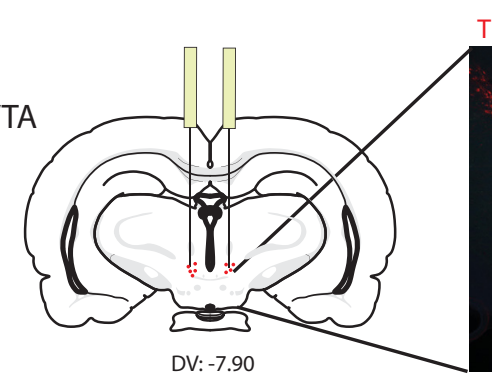

DV: -7.90
$\mathrm{TH}$

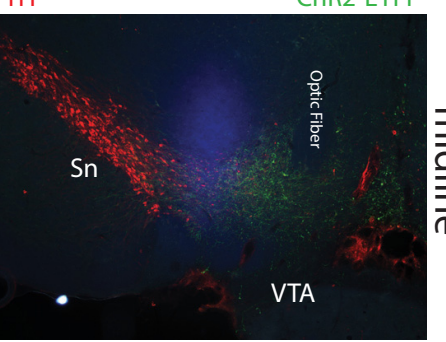

Mock

Stim

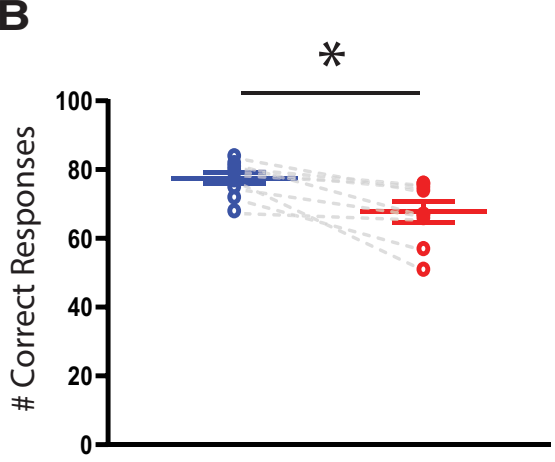

C
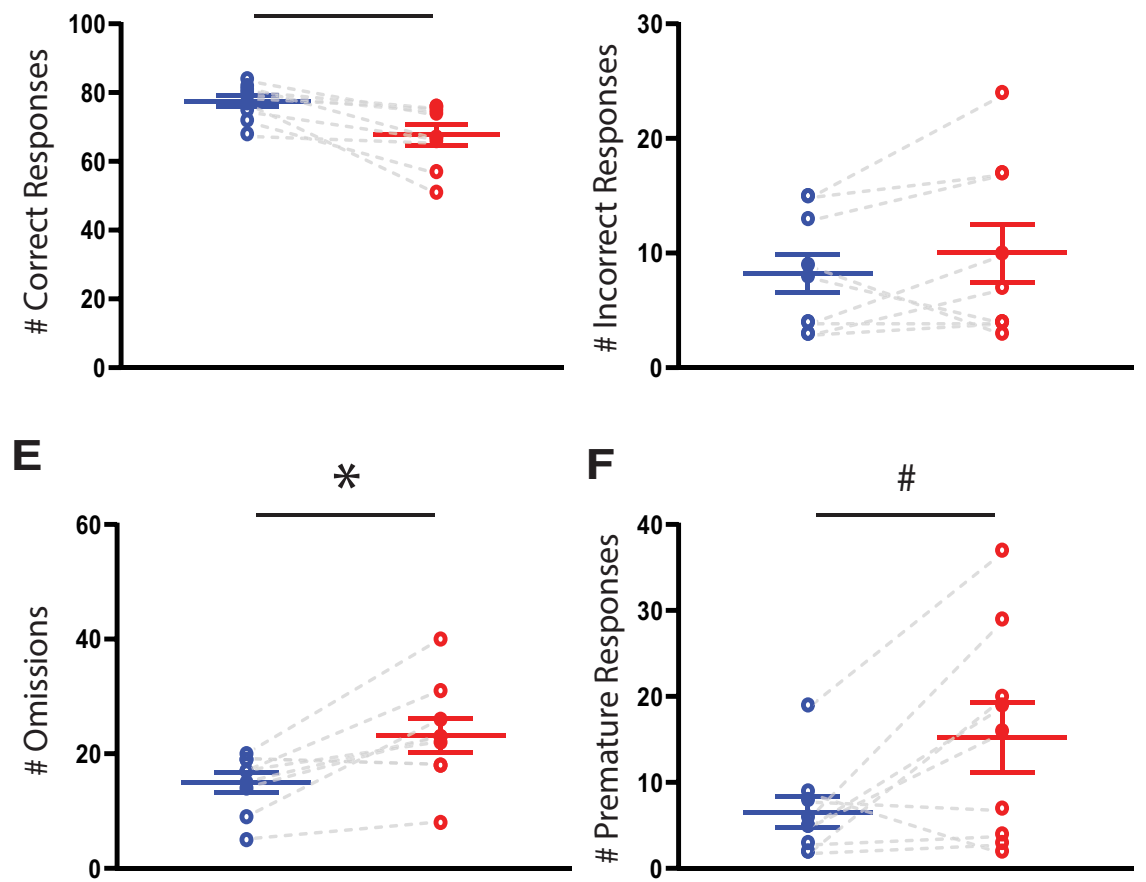

F

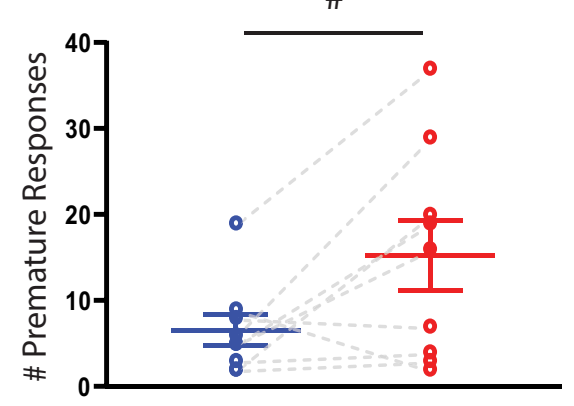

D

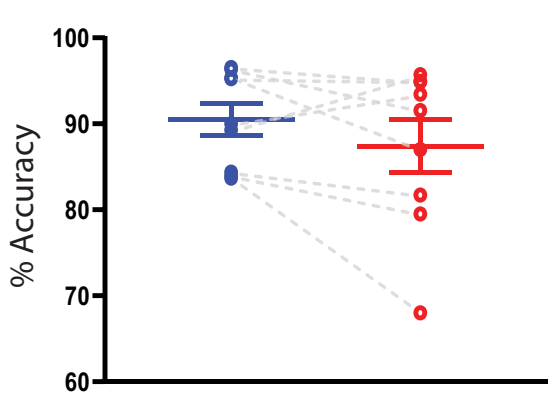

G

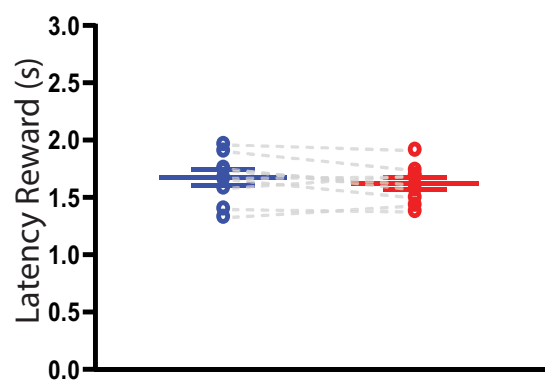

Figure 3. Stimulation of VTA to NAcbS projections in the 5-CSRTT. $\boldsymbol{A}$, Infusion of the Cre-dependent AAV5-Ef1a-DI0-hChR2-(H134R)-EYFP viral vector into the VTA and infusion of the retrograde viral vector Cav2-Cre into the NAcbS (left). Immunofluorescence of TH (red) and ChR2-EYFP (green) in the VTA (right). B-G, Correct responses, incorrect responses, accuracy, omissions, premature responses, and latency to retrieve the reward during mock and stimulation sessions, respectively $(n=9)$. Stimulation took place in the last $3 \mathrm{~s}$ of the ITI at $20 \mathrm{~Hz}$. Data are presented as mean \pm SEM; $* p<0.025$ when compared with mock stimulation (paired sample Student's $t$ test); \# indicates a trend $0.025<p<0.05$.

responses, and the latencies to correct, reward, premature, and incorrect responses were not affected by stimulation $\left(W=-15, p=0.06 ; t_{(8)}=1.6, p=0.14 ; t_{(8)}=1.7, p=0.12\right.$; $t_{(8)}=0.40, p=0.68 ; t_{(7)}=0.87, p=0.41$, respectively; Table $1)$. These observed changes were similar to those observed during the 5-s ITI stimulation session.

Stimulation of VTA-NAcbS projections (Fig. 6G-K) increased the number of premature responses $\left(t_{(8)}=3.16, p=0.014\right.$; Fig. $\left.6 K\right)$ and omissions $\left(t_{(8)}=2.9, p=0.02\right.$; Fig. $\left.6 \mathrm{~J}\right)$, decreased the number of correct responses $\left(t_{(8)}=4.8, p=0.001\right.$; Fig. $\left.6 G\right)$ but did not alter accuracy $\left(t_{(8)}=1.1, p=0.31\right.$; Fig. $\left.6 I\right)$ or the number of incorrect responses $\left(t_{(8)}=1.8, p=0.12\right.$; Fig. $\left.6 H\right)$. Perseverative responses, and the latencies to correct, reward, premature, and incorrect responses were not affected by stimulation $(W=2, p=0.91 ; W=8, p=0.66$; $t_{(8)}=0.20, p=0.85 ; W=13, p=0.50 ; W=13, p=0.50$, respectively; Table 1). The observed changes were similar to those found during the 5-s ITI stimulation session, and corroborated the observed trend in premature responses

Stimulation of VTA-NAcbC projections (Fig. 6L-P) showed an upwards trend in the number of premature responses $\left(t_{(7)}=\right.$
3.6, $p=0.03$; Fig. 6P). Moreover, unlike during the 5-s ITI session, no effects were observed on correct responses $\left(t_{(7)}=0.74\right.$, $p=0.9$; Fig. $6 L)$ or omissions $\left(t_{(7)}=0.91, p=0.4\right.$; Fig. 60$)$. Incorrect responses $\left(t_{(7)}=0.10, p=0.9\right.$; Fig. $\left.6 M\right)$, accuracy $\left(t_{(7)}=\right.$ $0.18, p=0.8$; Fig. $6 N$ ) perseverative responses, and the latencies to correct, reward, premature, and incorrect responses were not affected by stimulation $\left(W=1, p=0.99 ; t_{(7)}=1.28, p=0.24 ; t_{(7)}=\right.$ $0.71, p=0.50 ; W=-16, p=0.31 ; t_{(7)}=0.42, p=0.68$, respectively; Table 1).

Activating VTA-mPFC projections (Fig. 6Q- $U$ ) did not alter correct responses $\left(t_{(8)}=1.3, p=0.25\right.$; Fig. 6Q), incorrect responses $\left(t_{(8)}=1.4, p=0.213\right.$; Fig. $\left.6 R\right)$ or accuracy $\left(t_{(8)}=1.2\right.$, $p=0.26$; Fig. $6 S$ ) in contrast to what we observed during the 5-s ITI stimulation session. However, the number of omissions was increased $\left(t_{(8)}=2.9, p=0.018\right.$; Fig. 6T). Premature responses $\left(t_{(8)}=1.6, p=0.15\right.$; Fig. $\left.6 U\right)$, perseverative responses, or the latencies to correct, reward, premature, and incorrect responses were not affected by stimulation $\left(W=0, p=0.99 ; t_{(8)}=1.27, p=0.24\right.$; $t_{(8)}=0.85, p=0.42 ; t_{(8)}=1.0, p=0.35 ; t_{(8)}=2.0, p=0.08$, respectively; Table 1). 
A

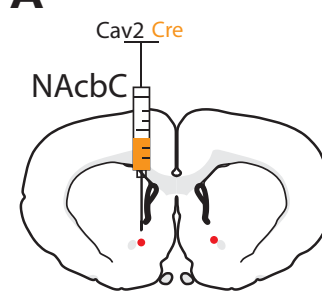

AP: 1.20 ML:1.60 DV: -6.80

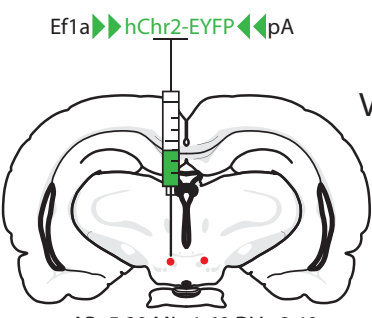

AP:-5.80 ML: 1.60 DV: -8.40

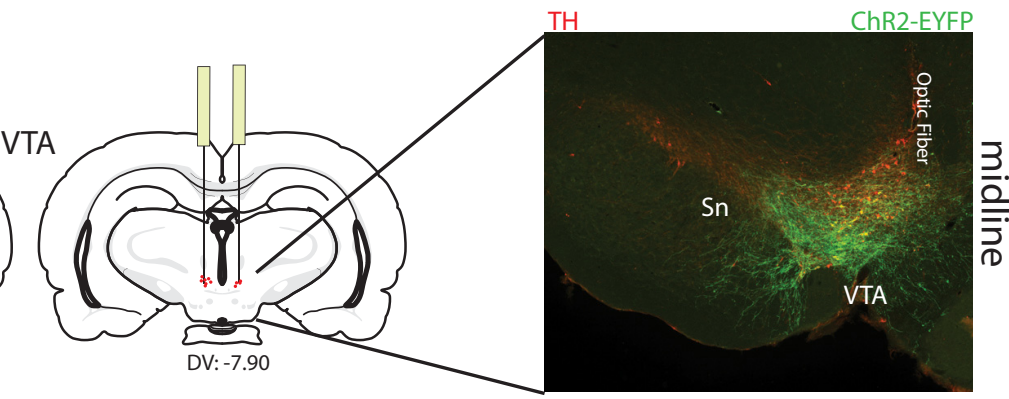

B

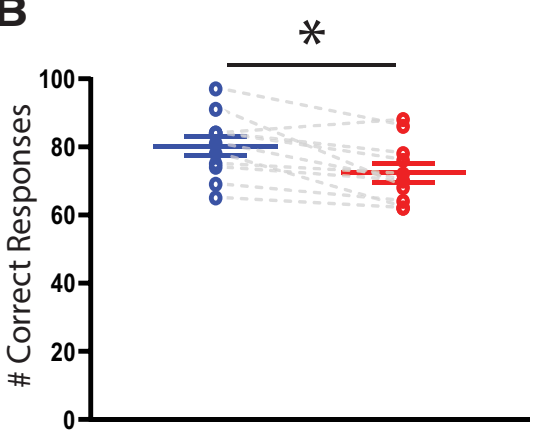

E

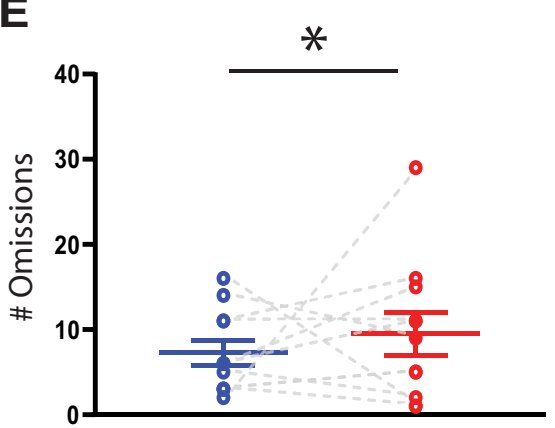

C

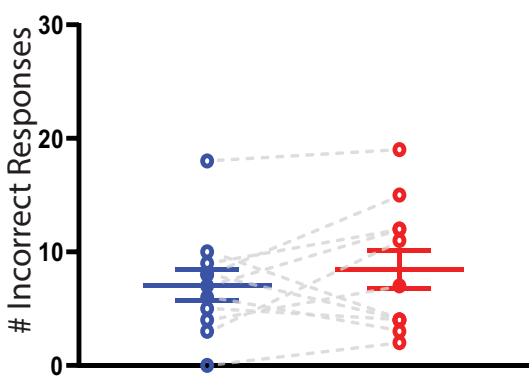

F

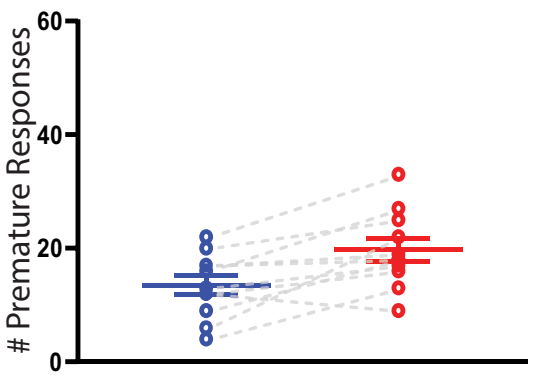

D

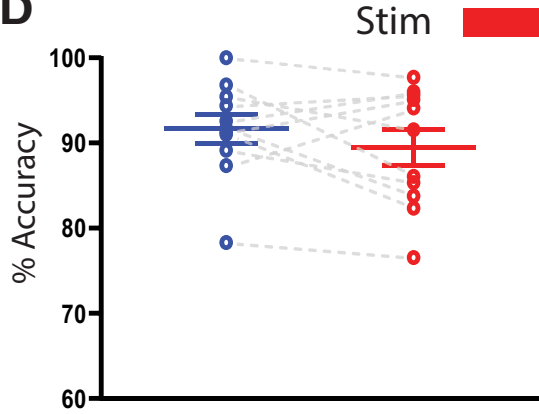

G

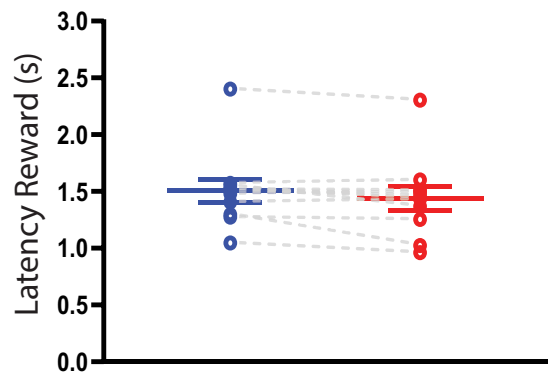

Figure 4. Stimulation of VTA to NAcbC projections in the 5-CSRTT. $A$, Infusion of the Cre-dependent AAV5-Ef1a-DI0-hChR2-(H134R)-EYFP viral vector into the VTA and infusion of the retrograde viral vector Cav2-Cre into the NAcbC (left). Immunofluorescence of TH (red) and ChR2-EYFP (green) in the VTA (right). $\boldsymbol{B}-\boldsymbol{G}$, Correct responses, incorrect responses, accuracy, omissions, premature responses, and latency to retrieve the reward during mock and stimulation sessions, respectively $(n=11)$. Stimulation took place in the last $3 \mathrm{~s}$ of the ITI at $20 \mathrm{~Hz}$. Data are presented as mean \pm SEM; $* p<0.025$ when compared with mock stimulation (paired sample Student's $t$ test); \# indicates a trend $0.025<p<0.05$.

Effect of VTA DA, VTA-NAcbS, VTA-NAcbC, and VTAmPFC stimulation during the ITI onset

Lastly, we sought to test the time-locked nature of our manipulations by stimulating at the onset, instead of the end of the ITI (Fig. 7). Stimulation of VTA DA neurons (Fig. 7A-E) at the start of the ITI increased the number of omissions $\left(t_{(15)}=4.4\right.$, $p=0.0005$; Fig. $7 D)$ and decreased correct responses $\left(t_{(15)}=4.9\right.$, $p=0.0002$; Fig. $7 A$ ), but it did not affect incorrect response, accuracy, or premature responses $\left[t_{(15)}=0.17, p=0.86\right.$ (Fig. $7 B$ ); $t_{(15)}=1.25, p=0.23$ (Fig. $7 C$ ); $t_{(15)}=1.10, p=0.29$ (Fig. $7 E$ )]. It also had no effect on correct, premature, or incorrect latencies $\left(t_{(15)}=1.30, p=0.21 ; t_{(14)}=0.24, p=0.81 ; t_{(15)}=2.1, p=0.054\right.$; Table 1) but did decrease the number of perseverative responses ( $W=-81, p=0.008$; Table 1 ) and marginally reduced the latency to reward $\left(t_{(15)}=4.81, p=0.0002\right.$; Table 1$)$. In contrast to stimulation at the end of the ITI, activating VTA projections toward the NAcbS during the onset of the ITI (Fig. $7 F-J$ ) did not affect correct responses, incorrect responses, accuracy, omission or premature responses $\left[t_{(8)}=1.9, p=0.09\right.$ (Fig. $\left.7 F\right) ; t_{(8)}=0.43$, $p=0.68$ (Fig. $7 G$ ); $t_{(8)}=0.06, p=0.94$ (Fig. $7 H$ ); $t_{(8)}=2.19$, $p=0.06$ (Fig. $7 I) ; t_{(8)}=0.87, p=0.41$ (Fig. $\left.7 J\right)$ ]. It also did not affect perseverative responses and correct, reward and incorrect latencies $(W=-13, p=0.49 ; W=8, p=0.66 ; W=-15, p=0.42$; $t_{(6)}=0.83, p=0.44$, respectively; Table 1$)$ but tended to increase premature response latency $\left(t_{(7)}=2,7 ; p=0.03\right.$; Table 1). Activation of VTA-NAcbC projections (Fig. $7 \mathrm{~K}-\mathrm{O}$ ) increased the number of omissions $\left(t_{(6)}=3.0, p=0.02\right.$; Fig. $\left.7 N\right)$ and tended to decrease correct responses $\left(t_{(6)}=2.5, p=0.045\right.$; Fig. $\left.7 K\right)$ but did not alter incorrect responses, accuracy, or premature responses $\left[t_{(6)}=0.30, p=0.77\right.$ (Fig. $7 L$ ); $t_{(6)}=0.55, p=0.60$ (Fig. $7 M) ; t_{(6)}=0.4, p=0.7$ (Fig. 7O)]. It also did not affect perseverative responses or correct, reward, premature, or incorrect laten$\operatorname{cies}\left(t_{(6)}=0.54, p=0.6 ; t_{(6)}=1.4, p=0.21 ; W=0, p=0.99 ; t_{(5)}=\right.$ $0.90, p=0.41 ; t_{(6)}=0.47, p=0.66$, respectively; Table 1$)$. Lastly, stimulation of VTA projections to the mPFC during the ITI onset had no effect on correct responses, incorrect responses, accuracy, omission or premature responses $[t=0.83, p=0.43$ (Fig. $7 P) ; t_{(6)}=0.88, p=0.41($ Fig. $7 Q) ; t_{(6)}=0.55, p=0.60$ (Fig. $7 R$ ); $t_{(6)}=1.83, p=0.11$ (Fig. 7S); $t_{(6)}=0.57, p=0.58$ (Fig. 7T)] or on perseverative responses or correct, reward, premature, or 
A

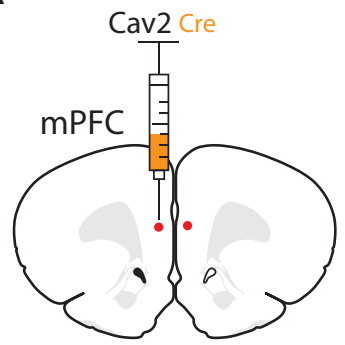

AP: $2.70 \mathrm{ML}: 1.20 \mathrm{DV}:-5.70$

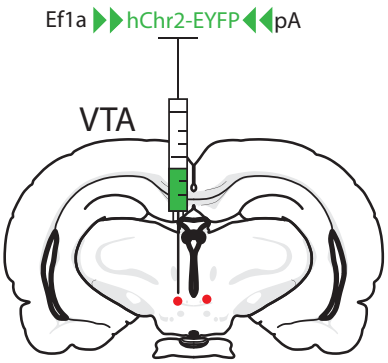

AP:-5.80 ML: 1.60 DV: -8.40

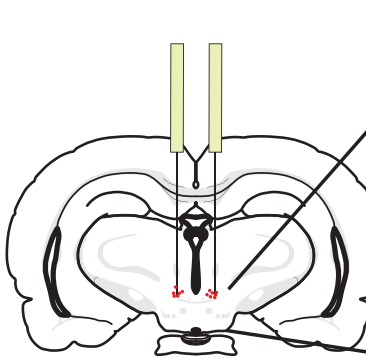

DV: -7.90

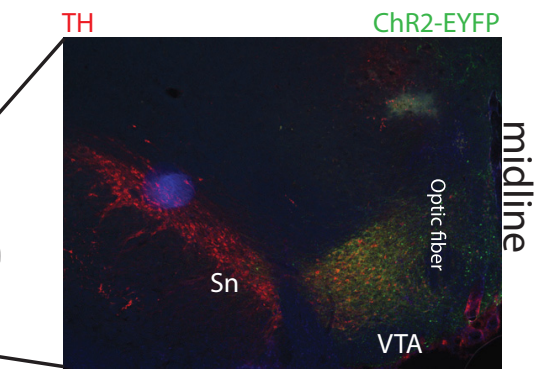

Mock
B

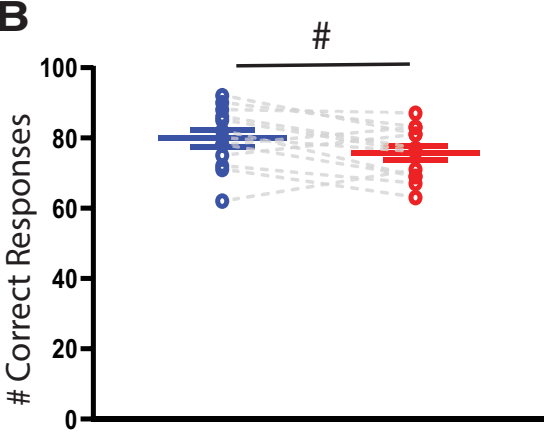

E

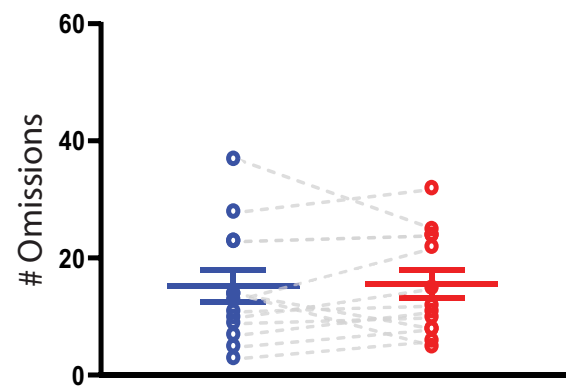

C

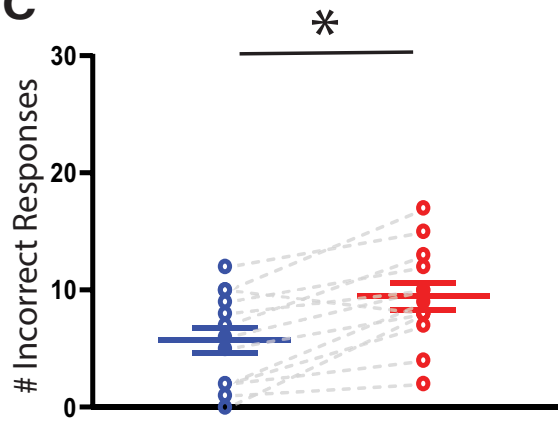

$F$

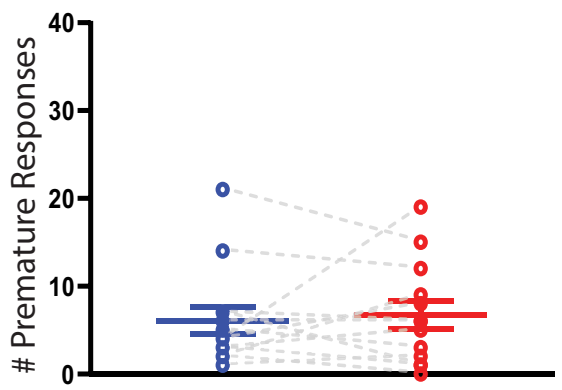

Stim

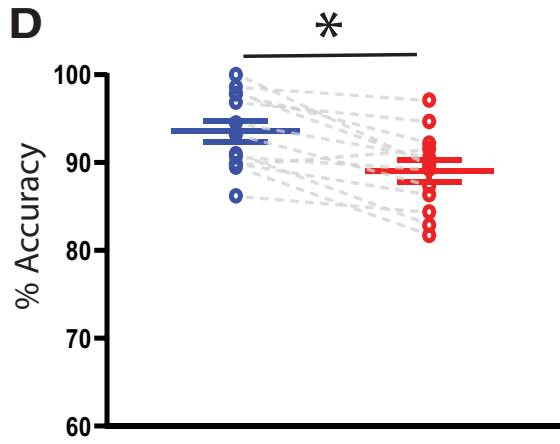

G

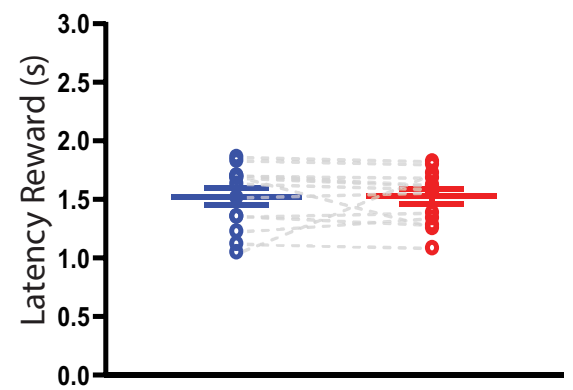

Figure 5. Stimulation of VTA to mPFC projections in the 5-CSRTT. $\boldsymbol{A}$, Infusion of the (re-dependent AAV5-Ef1a-DI0-hChR2-(H134R)-EYFP viral vector into the VTA and infusion of the retrograde viral vector Cav2-Cre into the mPFC (left). Immunofluorescence of TH (red) and ChR2-EYFP (green) in the VTA (right). B-G, Correct responses, incorrect responses, accuracy, omissions, premature responses, and latency to retrieve the reward during mock and stimulation sessions, respectively $(n=13)$. Stimulation took place in the last $3 \mathrm{~s}$ of the ITI at $20 \mathrm{~Hz}$. Data are presented as mean \pm SEM; $* p<0.025$ when compared with mock stimulation (paired sample Student's $t$ test); \# indicates a trend $0.025<p<0.05$.

incorrect latencies $\left(W=-7, p=0.64 ; W=14, p=0.30 ; t_{(6)}=\right.$ $1.33, p=0.23 ; t_{(5)}=0.16, p=0.88 ; t_{(5)}=0.028, p=0.98$, respectively; Table 1).

\section{Discussion}

We determined how activation of ascending VTA projections affects attention and impulse control in the 5-CSRTT. Our findings show that time-locked optogenetic stimulation of VTA DA neurons induces attentional impairments, by reducing the number of correct responses and increasing response omissions. Stimulating VTA projections toward the NAcbC and the NAcbS reproduced these attentional deficits. Importantly, activating VTA-NAcbS projections also increased impulsive behavior when the animals were tested under longer ITI conditions to provoke impulsive behavior. Finally, stimulating VTA-mPFC projections impaired attention by reducing accuracy. These effects strongly depended on when stimulation was applied, as most of the effects were only found when optogenetic stimulation was applied at the end of the ITI. These results demonstrate a temporally specific role of different VTA output projections in distinct aspects of attention and impulsive action.

Optogenetic stimulation of VTA DA cell bodies impaired attention but did not alter impulsive behavior in the 5-CSRTT. This is consistent with our previous findings of chemogenetic stimulation of VTA DA neurons (Boekhoudt et al., 2017). A previous study found sustained increases in VTA DA cellular activity before stimulus presentation in a three-choice task, perhaps reflecting preparatory attention (Totah et al., 2013). By disrupting these preparatory VTA DA signals, our stimulation protocol may have induced a deficit in sustained attention. Consistently, systemic treatment with amphetamine has also been shown to increase omissions (Cole and Robbins, 1989; van Gaalen et al., 2006; Pezze et al., 2007; Pattij and Vanderschuren, 2008; Besson et al., 2010; Baarendse and Vanderschuren, 2012), although the most well-known effect of amphetamine in the 5-CSRTT is to increase premature responses and reduce response latencies. This latter effect resonates with the involvement of DA in 


\section{7 second ITI challenge}

A

\section{7s ITI Challenge}

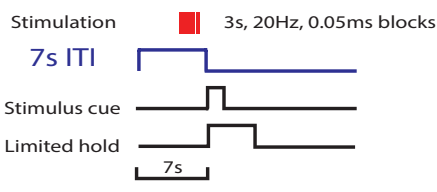

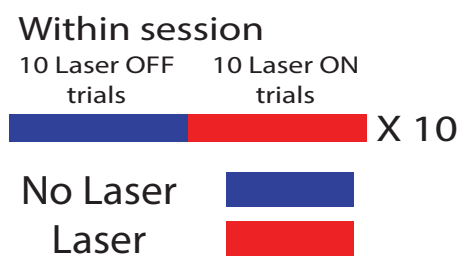
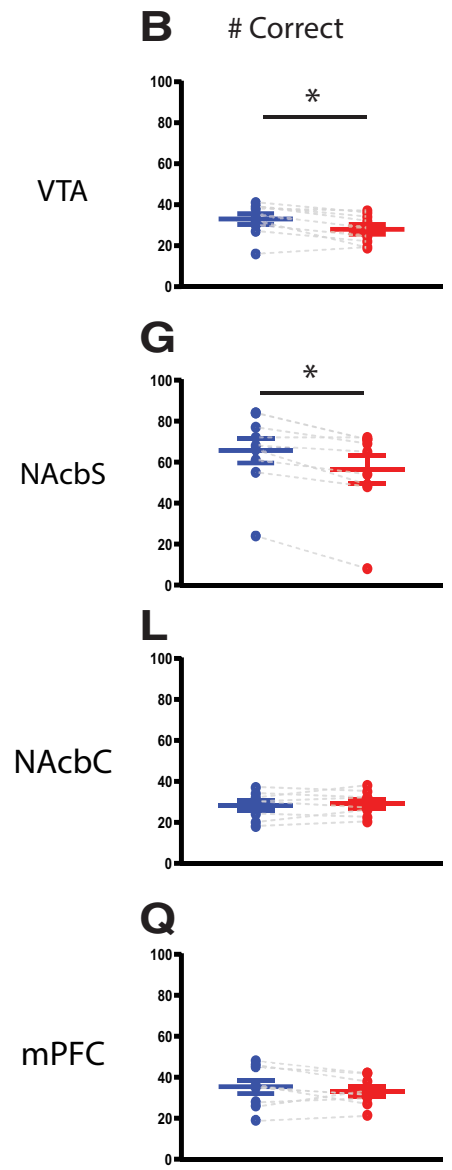
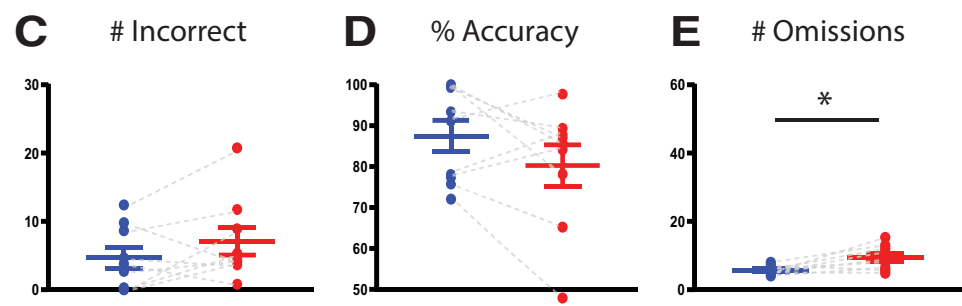

F \# Premature
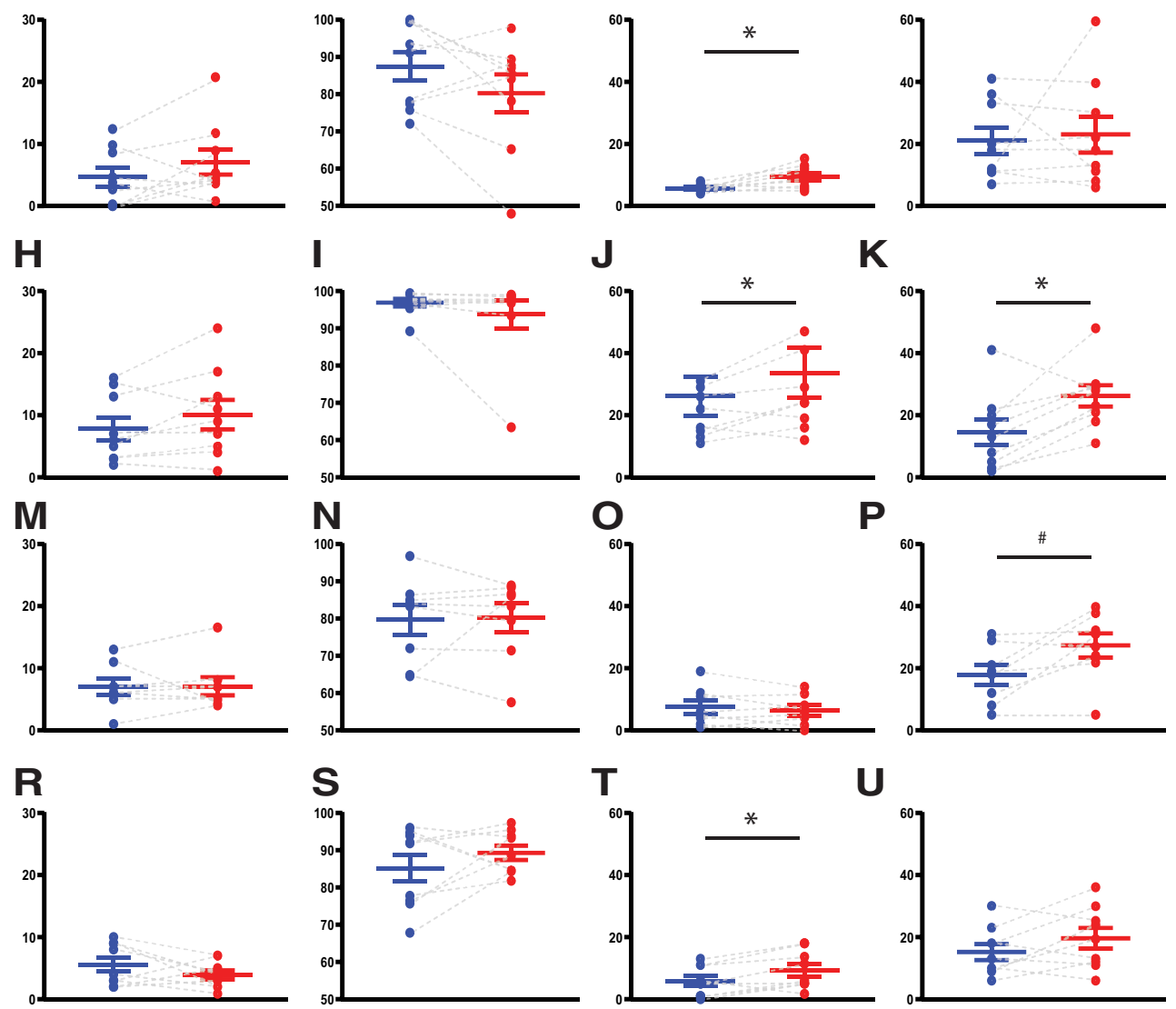

Figure 6. Stimulation of VTA DA neurons and VTA projections to the NAcbS, the NAcbC or the mPFC during a 7-s ITI challenge in the 5-CSRTT. $A$, Diagram depicting the 7-s ITI challenge of the 5-CSRTT (left). Schematic showing the division of laser and no-laser trials within a session during a 7-s ITI challenge (right). $\boldsymbol{B}-\boldsymbol{F}$, Correct responses, incorrect responses, accuracy, omissions, and premature responses during mock and stimulation trials for the VTA DA group $(n=9)$. $\mathbf{G}-\boldsymbol{K}$, As previous for the VTA to NAcbS group $(n=9)$. $\triangleq$ one animal in $\boldsymbol{J}$ is not shown (out of upper bounds). $\boldsymbol{L}-\boldsymbol{P}$, As previous for the NAcbC group $(n=8)$. $\mathbf{Q}-\boldsymbol{U}$, As previous for the VTA to mPFC group $(n=9)$. Data are presented as mean \pm SEM; $* p<0.025$ when compared with mock stimulation trials (paired samples Student's $t$ test); \# indicates a trend $0.025<p<0.05$.

incentive motivation (Robbins and Everitt, 2007; Salamone and Correa, 2012) and reward-prediction error signaling (Schultz et al., 1997). However, we hardly observed changes in response or reward collection latencies. Thus, by restricting our manipulation of VTA DA cells to timepoints outside of presentation of the cue and the reward, we left task motivation and impulse control intact.

Stimulating either VTA-NAcbC or VTA-NAcbS projections evoked similar attentional deficits as those seen during broad VTA DA neuron activation. This concurs with the increases in omissions after intra-NAcb amphetamine injections (Cole and Robbins, 1989). However, intra-NAcb infusions of DA D1 or D2 receptor antagonists increased errors of omission, whereas intraNAcb infusion of a D1 receptor agonist decreased omissions, but at a low dose only (Pezze et al., 2007; Moreno et al., 2013). These findings suggest that optimal attentive performance depends on a fine balance of NAcb DA activity, whereby the increase in omissions after VTA-NAcbC and NAcbS stimulation may be driven by overstimulation of DA D1 receptors. Furthermore, our results suggest that ascending projections from the VTA to the NAcbC and NAcbS play comparable roles in attentive behavior in the 5-CSRTT (see also Pattij et al., 2007). Although stimulation of the VTA-NAcb pathways is not specific to DA neurons, we think that these effects are mediated by DA. Thus, $\sim 80 \%$ of the VTA neurons targeted are DAergic (Boender et al., 2014; Verharen et al., 2018), and stimulation of the VTA-NAcb pathways yielded comparable results as stimulation of VTA DA cells. The behavioral effects of stimulation of non-DA (GABAergic and glutamatergic) ascending VTA projections are difficult to reconcile with our findings, as stimulation of VTA GABA 


\section{ITI onset stimulation}
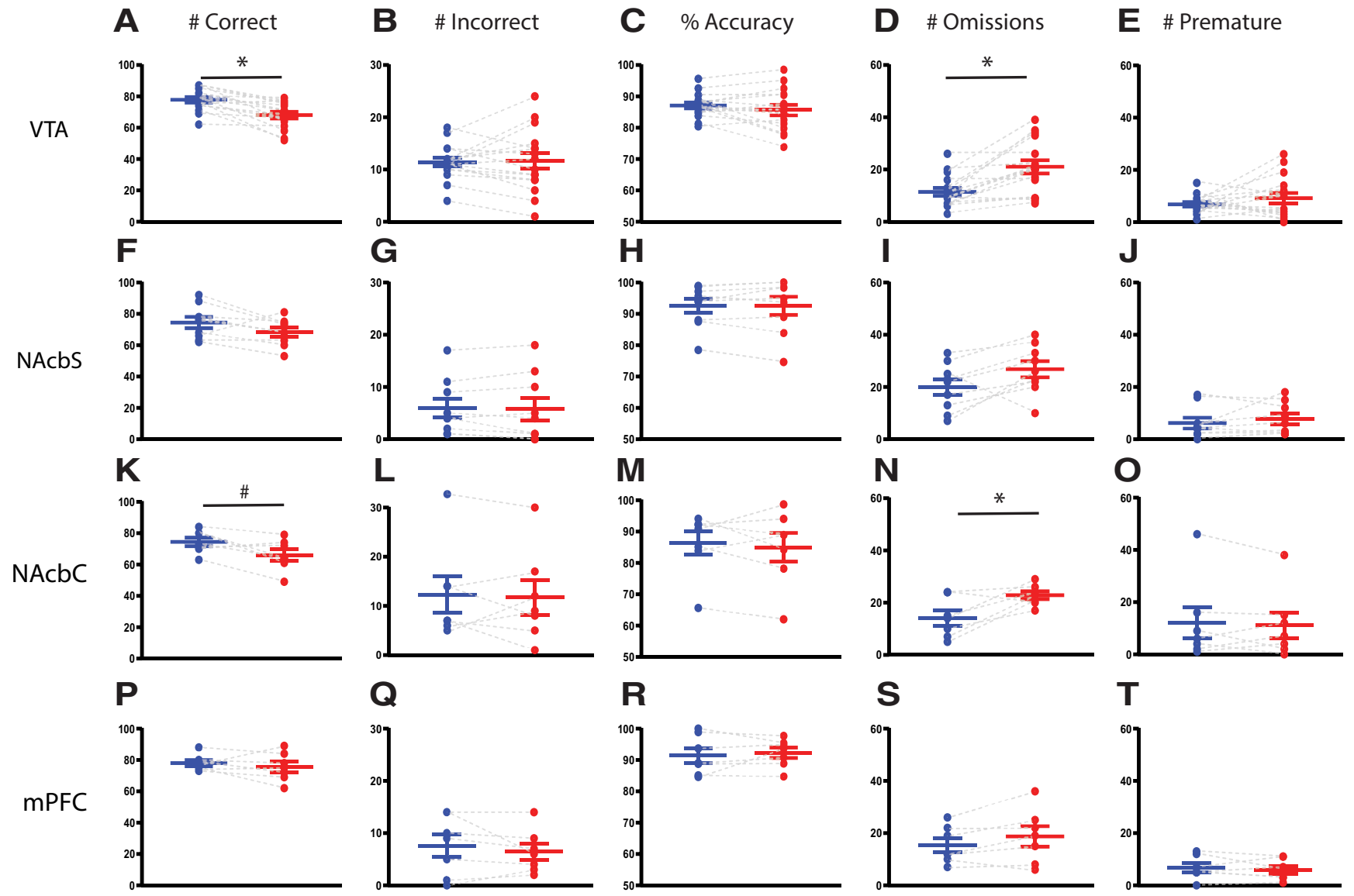

Figure 7. Stimulation at ITI onset of VTA DA neurons and VTA projections to the NAcbS, the NAcbC or the mPFC in the 5-CSRTT. A-E, Correct responses, incorrect responses, accuracy, omissions, and premature responses during mock and stimulation sessions for the VTA DA group $(n=16)$. $\boldsymbol{F}-\boldsymbol{J}$, As previous for the VTA to NAcbS group $(n=9)$. $\boldsymbol{K}-\boldsymbol{0}$, As previous for the NAcbC group $(n=7)$. J, $\mathbf{P}-\boldsymbol{T}$, As previous for the VTA to $\mathrm{mPFC}$ group $(n=7)$. Data are presented as mean \pm SEM; $* p<0.025$ when compared with mock stimulation session (paired samples Student's $t$ test); \# indicates a trend $0.025<p<0.05$.

neurons did not result in motivational or attentional impairments (van Zessen et al., 2012), stimulation of glutamatergic VTA-NAcb fibers caused aversive responses (Qi et al., 2016) and intra-NAcb infusion of a GABA-A receptor agonist resulted in a profound overall reduction in 5-CSRTT task engagement (Feja et al., 2014).

Previous studies have shown that NAcb DA plays a prominent role in the modulation of premature responding in the 5CSRTT (Cole and Robbins, 1987, 1989; Pattij et al., 2007; Economidou et al., 2012; Moreno et al., 2013). Indeed, we found an increase in impulsive behavior during 7-s ITI sessions when stimulating the VTA-NAcbS pathway, whereas a trend toward this effect was observed when stimulation was applied during baseline sessions. Stimulation of this pathway at the onset of the ITI did not trigger an increase in premature responses, indicating that modulation of impulse control by NAcbS mechanisms occurs in a temporally precise manner. Previous single-unit recordings have suggested that premature responding occurs because of early ramping activity in the NAcb leading to a maximum of activity before the cue in the 5-CSRTT (Donnelly et al., 2015). By stimulating neurons at the end of the ITI we may therefore mimic the activity maxima in the NAcb associated with premature responses, whereas ITI onset stimulation may not increase NAcb activity such that it induces premature responding. We also found that the increases in premature responding after VTA-NAcbS stimulation dissipated over the session (data not shown), suggesting an adaptive mechanism wherein NAcb cells adjust ramping activity to the stimulation.

Under baseline conditions, stimulation of the VTA-NAcbC pathway did not increase premature responding. However, under conditions when impulse control was challenged, using a longer ITI, stimulation of the VTA-NAcbS increased premature responses, whereas an upward trend in premature responses was observed during stimulation under increased ITI conditions in the NAcbC group. These findings indicate that the NAcbS, and to a lesser degree the NAcbC, become particularly engaged under higher cognitive load. The difference of effect between the NAcbC and the NAcbS stimulation is supported by the findings that DA dynamics in these regions differ between high-impulsive versus low-impulsive rats (Diergaarde et al., 2008; Jupp et al., 2013) and that treatment with DAergic drugs into the NAcbS and NAcbC differentially affect premature responding in highimpulsive versus low-impulsive rats in the 5-CSRTT (Besson et al., 2010; Moreno et al., 2013).

Recent studies have shown that optogenetic stimulation of VTA DA cells, as well as VTA-NAcb projections, is reinforcing 
(Witten et al., 2011; Lammel et al., 2012; Ilango et al., 2014; Pascoli et al., 2015; Hamid et al., 2016; Saunders et al., 2018). Task performance may therefore have been disrupted as a result of reinforcement of prestimulus task-irrelevant behaviors (i.e., grooming). It is important to note, however, that specific taskirrelevant behaviors were not consistently reinforced, since there was no contingency of any particular behavior with stimulation. Also, task-relevant behaviors, such as scanning the stimulus light array could have been reinforced as well, likely resulting in positive effects on task performance. Moreover, the pattern of effects of VTA DA cell stimulation on attentional parameters is comparable to our previous findings with chemogenetic VTA DA cell stimulation, not restricted to certain task epochs or behaviors (Boekhoudt et al., 2017). Thus, although we cannot rule out a contribution of incidental reinforcement of task-irrelevant behavior, it is improbable that this is driving the observed attentional deficits.

The involvement of the mPFC in attention and impulsivity in the 5-CSRTT has been extensively explored (Muir et al., 1996; Robbins, 2002; Dalley et al., 2008). Our experiments found no increases in premature responses when targeting the VTAmPFC projection. This falls in line with previous studies showing no change in premature responding after infusion of methylphenidate into the mPFC (Economidou et al., 2012), as well as the lack of differences in mPFC DA neurotransmission between high-impulsive and low-impulsive rats (Diergaarde et al., 2008; Jupp et al., 2013). Thus, although the mPFC has been implicated in inhibitory control (Muir et al., 1996; Robbins, 2002; Dalley et al., 2008; Verharen et al., 2019), this is not driven by activity stemming from the VTA (Verharen et al., 2020). Attentional performance was significantly reduced when VTA-mPFC projections were stimulated, consistent with previous work showing that response accuracy in the 5-CSRTT depends on optimal signaling through DA D1 receptors (Granon et al., 2000). VTA$\mathrm{mPFC}$ inputs appeared to be particularly involved in attention immediately before cue onset, as the attentive deficits were only elicited when the VTA-mPFC projection was stimulated at the end of the ITI. This reduction in attention was driven by a decrease in accuracy, stemming from an increase in incorrect responses. This is unlike the attentional reductions observed after VTA DA and VTA-NAcb stimulations, which resulted from an increase in omissions and a reduction in correct responses. Thus, although stimulation of VTA-NAcb and the VTA-mPFC pathways both reduce attention, they do so through different mechanisms: the former reduces attending to the cue, whereas the latter increases the propensity of animals to make an incorrect guess. Lastly, we did not observe reduced accuracy or increased incorrect responses during the 7-s ITI challenge in the VTA$\mathrm{mPFC}$ group, perhaps because the increased cognitive load in terms of behavioral inhibition that this challenge poses masks any attentional deficits.

In conclusion, by stimulating ascending VTA neurons with projection-specificity and time-locked precision, we show dissociable deficits in attention and impulse control in the 5-CSRTT. Importantly, these deficits were mostly seen when stimulation was applied immediately preceding stimulus cue presentation, demonstrating that coordinated functional activity of distinct populations of ascending VTA neurons is required when explicit direction of cognitive resources at the source of information is needed.

\section{References}

Adamantidis AR, Tsai HC, Boutrel B, Zhang F, Stuber GD, Budygin EA, Tourino C, Bonci A, Deisseroth K, de Lecea L (2011) Optogenetic interrogation of dopaminergic modulation of the multiple phases of reward-seeking behavior. J Neurosci 31:10829-10835.

Baarendse PJJ, Vanderschuren LJMJ (2012) Dissociable effects of monoamine reuptake inhibitors on distinct forms of impulsive behavior in rats. Psychopharmacology (Berl) 219:313-326.

Bari A, Dalley JW, Robbins TW (2008) The application of the 5-choice serial reaction time task for the assessment of visual attentional processes and impulse control in rats. Nat Protoc 3:759-767.

Besson M, Belin D, McNamara R, Theobald DE, Castel A, Beckett VL, Crittenden BM, Newman AH, Everitt BJ, Robbins TW, Dalley JW (2010) Dissociable control of impulsivity in rats by dopamine $\mathrm{D} 2 / 3$ receptors in the core and shell subregions of the nucleus accumbens. Neuropsychopharmacology 35:560569.

Boekhoudt L, Voets ES, Flores-Dourojeanni JP, Luijendijk MC, Vanderschuren LJ, Adan RA (2017) Chemogenetic activation of midbrain dopamine neurons affects attention, but not impulsivity, in the five-choice serial reaction time task in rats. Neuropsychopharmacology 42:1315-1325.

Boender AJ, de Jong JW, Boekhoudt L, Luijendijk MCM, van der Plasse G, Adan RAH (2014) Combined use of the canine adenovirus- 2 and DREADD-technology to activate specific neural pathways in vivo. PLoS One 9:e95392.

Chudasama Y, Passetti F, Rhodes SEV, Lopian D, Desai A, Robbins TW (2003) Dissociable aspects of performance on the 5-choice serial reaction time task following lesions of the dorsal anterior cingulate, infralimbic and orbitofrontal cortex in the rat: differential effects on selectivity, impulsivity and compulsivity. Behav Brain Res 146:105-119.

Cole BJ, Robbins TW (1987) Amphetamine impairs the discriminative performance of rats with dorsal noradrenergic bundle lesions on a 5-choice serial reaction time task: new evidence for central dopaminergic-noradrenergic interactions. Psychopharmacology (Berl) 91:458-466.

Cole BJ, Robbins TW (1989) Effects of 6-hydroxydopamine lesions of the nucleus accumbens septi on performance of a 5-choice serial reaction time task in rats: implications for theories of selective attention and arousal. Behav Brain Res 33:165-179.

Dalley JW, Robbins TW (2017) Fractionating impulsivity: neuropsychiatric implications. Nat Rev Neurosci 18:158-171.

Dalley JW, Fryer TD, Brichard L, Robinson ESJ, Theobald DEH, Lääne K, Peña Y, Murphy ER, Shah Y, Probst K, Abakumova I, Aigbirhio FI, Richards HK, Hong Y, Baron JC, Everitt BJ, Robbins TW (2007) Nucleus accumbens D2/3 receptors predict trait impulsivity and cocaine reinforcement. Science 315:1267-1270.

Dalley JW, Mar AC, Economidou D, Robbins TW (2008) Neurobehavioral mechanisms of impulsivity: fronto-striatal systems and functional neurochemistry. Pharmacol Biochem Behav 90:250-260.

de Wit H (2009) Impulsivity as a determinant and consequence of drug use: a review of underlying processes. Addict Biol 14:22-31.

Diergaarde L, Pattij T, Poortvliet I, Hogenboom F, de Vries W, Schoffelmeer ANM, De Vries TJ (2008) Impulsive choice and impulsive action predict vulnerability to distinct stages of nicotine seeking in rats. Biol Psychiatry 63:301-308.

Donnelly NA, Paulsen O, Robbins TW, Dalley JW (2015) Ramping single unit activity in the medial prefrontal cortex and ventral striatum reflects the onset of waiting but not imminent impulsive actions. Eur J Neurosci 41:1524-1537.

Eagle DM, Baunez C (2010) Is there an inhibitory-response-control system in the rat? Evidence from anatomical and pharmacological studies of behavioral inhibition. Neurosci Biobehav Rev 34:50-72.

Economidou D, Theobald DE, Robbins TW, Everitt BJ, Dalley JW (2012) Norepinephrine and dopamine modulate impulsivity on the five-choice serial reaction time task through opponent actions in the shell and core sub-regions of the nucleus accumbens. Neuropsychopharmacology 37:2057-2066.

Feja M, Hayn L, Koch M (2014) Nucleus accumbens core and shell inactivation differentially affects impulsive behaviours in rats. Prog NeuroPsychopharmacology Biol Psychiatry 54:31-42.

Fineberg NA, Chamberlain SR, Goudriaan AE, Stein DJ, Vanderschuren LJMJ, Gillan CM, Shekar S, Gorwood PAPM, Voon V, Morein-Zamir S, Denys D, Sahakian BJ, Moeller FG, Robbins TW, Potenza MN (2014) New developments in human neurocognition: clinical, genetic, and brain imaging correlates of impulsivity and compulsivity. CNS Spectr 19:6989. 
Granon S, Passetti F, Thomas KL, Dalley JW, Everitt BJ, Robbins TW (2000) Enhanced and impaired attentional performance after infusion of D1 dopaminergic receptor agents into rat prefrontal cortex. J Neurosci 20:1208-1215.

Hamid AA, Pettibone JR, Mabrouk OS, Hetrick VL, Schmidt R, Vander Weele CM, Kennedy RT, Aragona BJ, Berke JD (2016) Mesolimbic dopamine signals the value of work. Nat Neurosci 19:117-126.

Ilango A, Kesner AJ, Keller KL, Stuber GD, Bonci A, Ikemoto S (2014) Similar roles of substantia nigra and ventral tegmental dopamine neurons in reward and aversion. J Neurosci 34:817-822.

Jupp B, Caprioli D, Saigal N, Reverte I, Shrestha S, Cumming P, Everitt BJ, Robbins TW, Dalley JW (2013) Dopaminergic and GABA-ergic markers of impulsivity in rats: evidence for anatomical localisation in ventral striatum and prefrontal cortex. Eur J Neurosci 37:1519-1528.

Lammel S, Lim BK, Ran C, Huang KW, Betley MJ, Tye KM, Deisseroth K, Malenka RC (2012) Input-specific control of reward and aversion in the ventral tegmental area. Nature 491:212-217.

Moeller FG, Barratt ES, Dougherty DM, Schmitz JM, Swann AC (2001) Psychiatric aspects of impulsivity. Am J Psychiatry 158:1783-1793.

Moreno M, Economidou D, Mar AC, López-Granero C, Caprioli D, Theobald DE, Fernando A, Newman AH, Robbins TW, Dalley JW (2013) Divergent effects of $\mathrm{D}_{2 / 3}$ receptor activation in the nucleus accumbens core and shell on impulsivity and locomotor activity in high and low impulsive rats. Psychopharmacology (Berl) 228:19-30.

Muir JL, Everitt BJ, Robbins TW (1996) The cerebral cortex of the rat and visual attentional function: dissociable effects of mediofrontal, cingulate, anterior dorsolateral, and parietal cortex lesions on a five-choice serial reaction time task. Cereb Cortex 6:470-481.

Murphy CA, Pezze MA, Feldon J, Heidbreder C (2000) Differential involvement of dopamine in the shell and core of the nucleus accumbens in the expression of latent inhibition to an aversively conditioned stimulus. Neuroscience 97:469-477.

Pascoli V, Terrier J, Hiver A, Lüscher C (2015) Sufficiency of mesolimbic dopamine neuron stimulation for the progression to addiction. Neuron 88:1054-1066.

Passetti F, Chudasama Y, Robbins TW (2002) The frontal cortex of the rat and visual attentional performance: dissociable functions of distinct medial prefrontal subregions. Cereb Cortex 12:1254-1268.

Pattij T, Vanderschuren LJMJ (2008) The neuropharmacology of impulsive behaviour. Trends Pharmacol Sci 29:192-199.

Pattij T, Janssen MCW, Vanderschuren LJMJ, Schoffelmeer ANM, van Gaalen MM (2007) Involvement of dopamine D1 and D2 receptors in the nucleus accumbens core and shell in inhibitory response control. Psychopharmacology (Berl) 191:587-598.

Pezze MA, Dalley JW, Robbins TW (2007) Differential roles of dopamine D1 and $\mathrm{D} 2$ receptors in the nucleus accumbens in attentional performance on the five-choice serial reaction time task. Neuropsychopharmacology 32:273-283.

Qi J, Zhang S, Wang HL, Barker DJ, Miranda-Barrientos J, Morales M (2016) VTA glutamatergic inputs to nucleus accumbens drive aversion by acting on GABAergic interneurons. Nat Neurosci 19:725-733.
Robbins T (2002) The 5-choice serial reaction time task: behavioural pharmacology and functional neurochemistry. Psychopharmacology (Berl) 163:362-380.

Robbins TW, Everitt BJ (2007) A role for mesencephalic dopamine in activation: commentary on Berridge (2006). Psychopharmacology (Berl) 191:433-437.

Rosvold HE, Mirsky AF, Sarason I, Bransome ED, Beck LH (1956) A continuous performance test of brain damage. J Consult Psychol 20:343-350.

Salamone JD, Correa M (2012) The mysterious motivational functions of mesolimbic dopamine. Neuron 76:470-485.

Saunders BT, Richard JM, Margolis EB, Janak PH (2018) Dopamine neurons create Pavlovian conditioned stimuli with circuit-defined motivational properties. Nat Neurosci 21:1072-1083.

Schultz W, Dayan P, Montague PR (1997) A neural substrate of prediction and reward. Science 275:1593-1599.

Sesia T, Temel Y, Lim LW, Blokland A, Steinbusch HWM, VisserVandewalle V (2008) Deep brain stimulation of the nucleus accumbens core and shell: opposite effects on impulsive action. Exp Neurol 214:135139.

Totah NKB, Kim Y, Moghaddam B (2013) Distinct prestimulus and poststimulus activation of VTA neurons correlates with stimulus detection. J Neurophysiol 110:75-85.

van Gaalen MM, Brueggeman RJ, Bronius PFC, Schoffelmeer ANM, Vanderschuren LJMJ (2006) Behavioral disinhibition requires dopamine receptor activation. Psychopharmacology (Berl) 187:73-85.

van Zessen R, Phillips JL, Budygin EA, Stuber GD (2012) Activation of VTA GABA neurons disrupts reward consumption. Neuron 73:1184-1194.

Verharen JPH, de Jong JW, Roelofs TJM, Huffels CFM, van Zessen R, Luijendijk MCM, Hamelink R, Willuhn I, den Ouden HEM, van der Plasse G, Adan RAH, Vanderschuren LJMJ (2018) A neuronal mechanism underlying decision-making deficits during hyperdopaminergic states. Nat Commun 9:731

Verharen JPH, van den Heuvel MW, Luijendijk M, Vanderschuren LJMJ, Adan RAH (2019) Corticolimbic mechanisms of behavioral inhibition under threat of punishment. J Neurosci 39:4353-4364.

Verharen JPH, Luijendijk MCM, Vanderschuren LJMJ, Adan RAH (2020) Dopaminergic contributions to behavioral control under threat of punishment in rats. Psychopharmacology (Berl) 237:1769-1782.

Voon V, Irvine MA, Derbyshire K, Worbe Y, Lange I, Abbott S, MoreinZamir S, Dudley R, Caprioli D, Harrison NA, Wood J, Dalley JW, Bullmore ET, Grant JE, Robbins TW (2014) Measuring "waiting" impulsivity in substance addictions and binge eating disorder in a novel analogue of rodent serial reaction time task. Biol Psychiatry 75:148-155.

Witten IB, Steinberg EE, Lee SY, Davidson TJ, Zalocusky KA, Brodsky M, Yizhar O, Cho SL, Gong S, Ramakrishnan C, Stuber GD, Tye KM, Janak PH, Deisseroth K (2011) Recombinase-driver rat lines: tools, techniques, and optogenetic application to dopamine-mediated reinforcement. Neuron 72:721-733. 